\title{
Research on Accurate Modeling and Control for Pneumatic Electric Braking System of Commercial Vehicle Based on Multi-Dynamic Parameters Measurement
}

\section{Yongtao Zhao}

China University of Geosciences Beijing https://orcid.org/0000-0001-8263-2746

\section{Yiyong Yang}

China University of Geosciences Being

Xiuheng Wu ( $\square$ wxh599@cau.edu.cn )

China Agricultural University, China

\section{Xingjun Tao}

China University of Geosciences Beijing

\section{Original Article}

Keywords: Vehicle dynamic, Pneumatic electric braking system, Brake system modeling, Proportional control

Posted Date: October 26th, 2020

DOI: https://doi.org/10.21203/rs.3.rs-95134/v1

License: (c) (1) This work is licensed under a Creative Commons Attribution 4.0 International License. Read Full License

Version of Record: A version of this preprint was published at Proceedings of the Institution of Mechanical Engineers, Part D: Journal of Automobile Engineering on February 25th, 2022. See the published version at https://doi.org/10.1177/09544070221078358. 


\section{Title page}

\section{Research on Accurate Modeling and Control for Pneumatic Electric Braking System of Commercial Vehicle Based on Multi-Dynamic Parameters Measurement}

Yong-Tao Zhao, born in 1991, is currently a PhD candidate at School of Engineering and Technology, China University of Geosciences (Beijing), China. He received his bachelor degree from Anhui Polytechnic University, China, in 2019. His research interests include electrical mechanical system design and vehicle dynamics.

E-mail: 1607972778@qq.com ; 3002190022@cugb.edu.cn

Yi-Yong Yang, born in 1966, is currently a professor at China University of Geosciences (Beijing), China. He received his PhD degree from Tsinghua University, China, in 2004. His research interests include vehicle dynamic, mechanical dynamics and control.

E-mail: yangyy@cugb.edu.cn

Xiu-Heng Wu, born in 1990, is currently an associate professor at China Agricultural University, China. He received his PhD degree from China Agricultural University, China, in 2018. His research interests include vehicle dynamics control, design and control of electric braking system, nonlinear time-frequency analysis and control.

E-mail: 594522801@qq.com; wxh599@cau.edu.cn

Xing-Jun Tao, born in 1993, is currently a master candidate at China University of Geosciences(BeiJing), China.

E-mail: 1689735300@qq.com

\section{Corresponding author: Xiu-Heng Wu E-mail: wxh599@cau.edu.cn Yi-Yong Yang E-mail: yangyy@cugb.edu.cn}




\title{
ORIGINAL ARTICLE
}

\section{Research on Accurate Modeling and Control for Pneumatic Electric Braking System of Commercial Vehicle Based on Multi-Dynamic Parameters Measurement}

\author{
Yong-Tao Zhao $^{1,3}$ • Yi-Yong Yang ${ }^{1,3} \cdot$ Xiu-Heng $\mathrm{Wu}^{2} \cdot$ Xing-Jun Tao $^{1}$
}

Abstract: Accurate pressure control and fast dynamic response are vital to the pneumatic electric braking system (PEBS) for that commercial vehicles require higher regulation precision of braking force on four wheels when braking force distribution is carried out under some conditions. Due to the lagging information acquisition, most feedback-based control algorithms are difficult to further improve the dynamic response of PEBS. Meanwhile, feedforward-based control algorithms like predictive control perform well in improving dynamic performance. but because of the large amount of computation and complexity of this kind of control algorithm, it cannot be applied in real-time on single-chip microcomputer, and it is still in the stage of theoretical research at present. To address this issue and for the sake of engineering reliability, this article presents a logic threshold control scheme combining analogous model predictive control (AMPC) and proportional control. In addition, an experimental device for real-time measuring PEBS multi-dynamic parameters is built. After correcting the key parameters, the precise model is determined and the influence of switching solenoid valve on its dynamic response characteristics is studied. For the control scheme, numerical and physical validation are executed to demonstrate the feasibility of the strategy and for the performance of the controller design. The experimental results show that the dynamic model of PEBS can accurately reflect its pressure characteristics. Furthermore, under different air source pressures, the designed controller can stably control the pressure output of PEBS and ensure that the error is within $8 \mathrm{KPa}$. Compared with the traditional control algorithm, the rapidity is improved by $32.5 \%$.

Keywords: Vehicle dynamic • Pneumatic electric braking system

$$
\begin{array}{ll}
\text { Xiu-Heng Wu } & \text { wxh599@cau.edu.cn } \\
\text { Yi-Yong Yang } & \text { yangyy@cugb.edu.cn }
\end{array}
$$

1 School of Engineering and Technology, China University of Geosciences (Beijing), Beijing, 100083, China

2 College of Engineering, China Agricultural University, Beijing, 100083, China

3 State Key of Automotive Safety and Energy, Tsinghua University, Beijing, 100084, China
- Brake system modeling • Proportional control

\section{Introduction}

Commercial vehicles have the characteristics of large mass, long body, high centroid, frequent braking and variable load, their braking safety and driving stability are easily affected by uneven distribution of braking force, which leads to frequent accidents such as vertical and horizontal skidding and rollover [1]. As an important component exerting braking force then implementing active stability control for commercial vehicles, PEBS adopts the combination of electronic control and traditional braking technology for braking. Compared with traditional braking, it can greatly improve the response speed during vehicle braking and reduce the braking distance. Furthermore, the driving safety has a high requirement for the precise pressure control of PEBS when a vehicle operates under extreme conditions such as sharp turn and sudden stop in which minor braking force fluctuation can lead to dynamic instability [2,3]. Besides, considering the characteristics of PEBS such a s rapid response, high amenity, electronic control and mechanical redundancy, it is expected to become the basic module of driverless commercial vehicles in future [4]. Therefore, research on how to get accurate and stable pressure of PEBS especial in extreme condition is significant to improve the safety of commercial vehicles.

In the PEBS of commercial vehicles, proportional servo valves and high-speed switch solenoid valves are two common pneumatic valves. According to the characteristics of them, their control mode is to control different pressures according to the input analog linear signal and pulse width modulation signal, respectively. Proportional valve is often used in traditional PEBS to regulate the braking pressure. For the research of proportional servo valve, the modeling and control methods of the valve are summarized [6,7]. High-speed switching solenoid valve is widely used because of its simple structure and low price. Pneumatic Brake-by-Wire 
Valve (PBWV) as the basic actuator of PEBS, uses high-speed switching solenoid valve group to control pressure [7,8]. Considering the inherent opening and closing characteristics of the solenoid valve, it is difficult to adjust the gas flow continuously and infinitely. [7]. In addition, compressed air as the power-transmitting medium in PEBS, because air is compressible, the braking pressure is susceptible to working conditions such as temperature and humidity. Moreover, different tubing and air source pressure also have different effects on the braking pressure $[9,10]$. Due to the deviation between the actual control input and the required input, the control accuracy will be reduced. These typical discrete characteristic affects the precise control of brake pressure.

The research and control of high-speed switch valve is the mainstream of the current research. For this kind of system with switching valve and strong nonlinearity, many significant works regarding PEBS nonlinearity analysis and modeling are available and based on these many methods are proposed to improve closed-loop performance. Among them, the reference [11-14] proposed to establish the dynamic model of the system based on the experimental data and carried on the application control. The discrete input open-loop system is equivalent to a continuous average input system model and the braking force is controlled by synovial control algorithm $[15,16]$. Palanivelu et al. [17] proposed an adaptive modeling method, after modeling the parts in the system, it is convenient to simulate the system and optimize the parameters to obtain the ideal braking performance. In order to obtain more accurate analysis results, some scholars start with the modeling and performance test of the basic original switching solenoid valve in the pneumatic braking system, and gradually analyze its impact on the whole braking system. Kong et al. [18] studied the stress process of the valve core of the solenoid valve according to the finite element analysis method, and its balance mathematical model is established. Most of the above methods are based on the study of a single dynamic parameter, few people synthesize multiple dynamic parameters to consider the nonlinear behaviors caused by the change of the system.

Model predictive control (MPC) has the characteristics of fast response, accurate control and high robustness $[19,20]$. Moreover, it plays a good control role in some discrete systems. It is based on the information of the past and the present moment, predicts the future output through the prediction model, and makes the deviation between the expected value and the actual value as small as possible in the finite time domain rolling optimization way, so as to achieve the optimal control of the system [21]. As an accurate control algorithm, MPC is difficult to be applied in single-chip microcomputer because of its large amount of calculation. Therefore, how to establish an accurate model and fast calculation has become a difficult problem to accurately control the braking pressure.

This paper first proposes a control architecture which combines MPC with traditional feedback control. Next, the precise model MPC will need is built using an experimental measuring device to obtain and modify several dynamic parameters. Based on the accurate model, the map diagram reflecting the system dynamic is established by simulating, and this map can be used to conduct the MPC. The rest of the paper is organized as follows. Section 2 analyses the working mechanism of the PEBS during braking and introduces the PEBS system model. Section 3 designs a controller based on the PEBS model. Section 4 sets up several experimental measuring devices for multiple dynamic parameters of PEBS to modified the model and verifies the control effect of the controller. Finally, the conclusion is presented in Section 5.

\section{Braking principle and PEBS model}




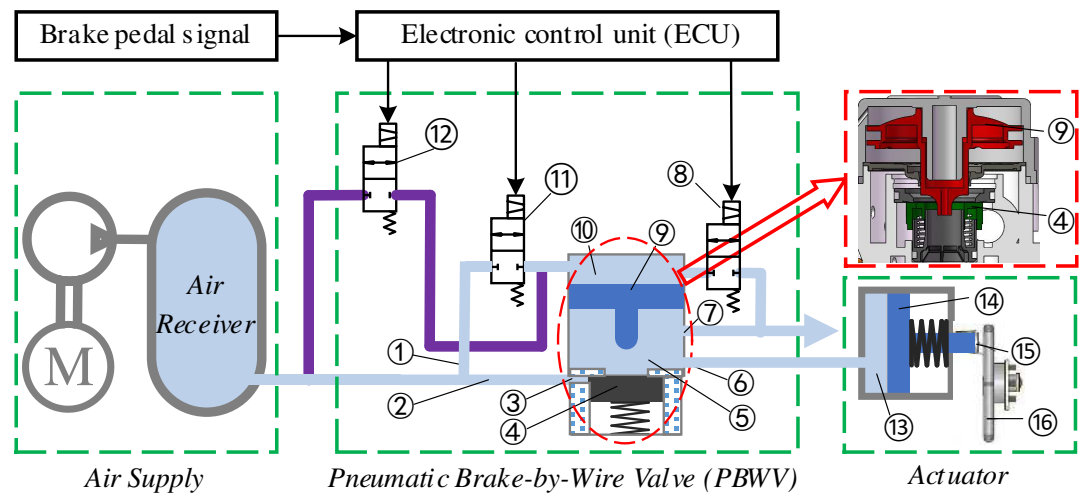

1.Pneumatic Control Line 2.Pneumatic Line 3.Inlet Port 4.Plug 5. Load Chamber 6.Outlet Port 7.Exhaust Port 8.Release Valve 9.Relay Valve Piston 10.Control Chamber 11.Inlet Valve 12.Backup Valve 13. Brake Chamber 14.Brake Cylinder Piston 15.Friction B lock 16.Brake Disc

Figure 1 Schematic diagram of Pneumatic Electric Braking System

\subsection{Braking Principle}

In PEBS, there are mainly PBWV and ABS valves to control the braking pressure. In order to facilitate the study of the pressure output of the PEBS, assuming that the circuit works normally and the wheel is not locked in the system, the PEBS is simplified. The simplified system is shown in Figure 1.

Figure.1 shows a general pneumatic electric braking system. The system consists of four components; namely, a control unit, an air supply system, a PBWV and an actuator. The PBWV includes an inlet valve, a release valve, a backup valve and a relay valve. The inlet valve and release valve belong to the high-speed switch valve that together are controlled by PWM (Pulse Width Modulation) signal.
The inlet valve inflates the control chamber and the release valve is used to discharge the air. The backup pressure valve is a switch valve that closes once the inlet valve or release valve is energized. The piston of the relay valve moves axially to increase or decrease the pressure of the actuator (brake air chamber).

Figure 2 defines the position of the relay valve piston and its corresponding working state. When the electric control circuit is working normally, the backup valve does not work, so the backup valve is not drawn in the figure. In Figure 2, three working states of the PBWV correspond to three working processes; namely, pressure increasing process, pressure holding process and pressure decreasing process.

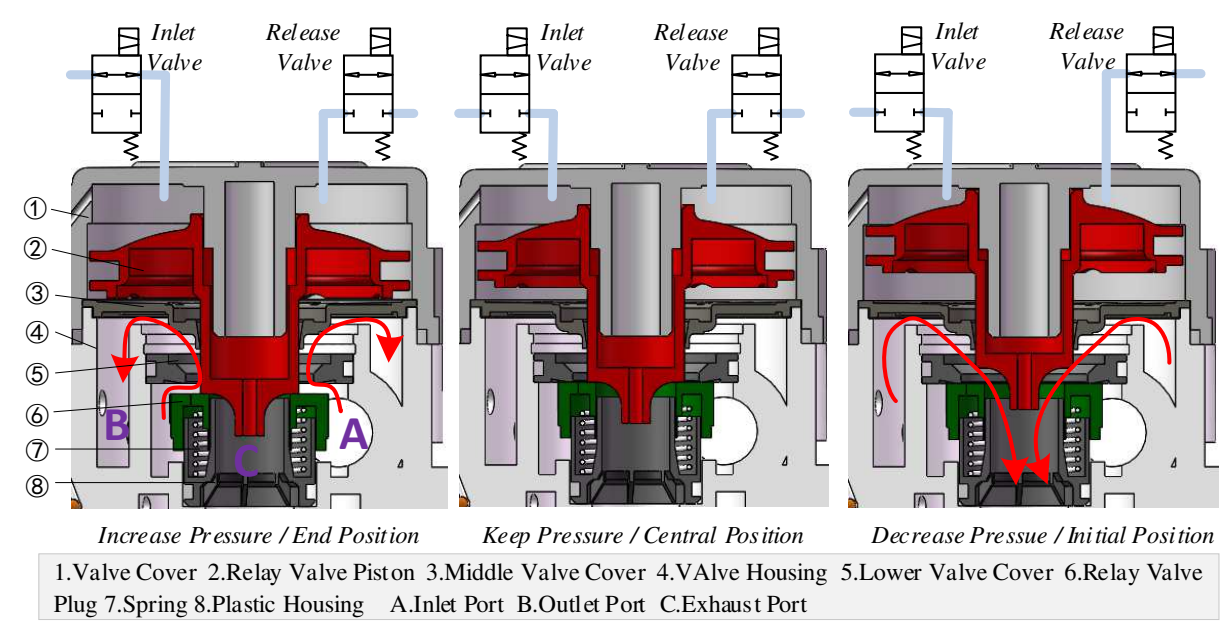

Figure 2 Relay valve piston position and corresponding working state

During pressure increasing process, the inlet valve opens and the release valve closes. The compressed air is mainly 
divided into the pneumatic line and the pneumatic control line into the PBMV. In the beginning, compressed air enters the control chamber along the pneumatic control line. As the pressure in the control chamber increases, the relay valve piston gradually overcomes the elastic force of the spring, the friction between the piston and the side wall, and the air pressure of the load cavity. The piston of the relay valve moves downward, which pushes the plug to separate from the lower valve cover, so that the compressed air in the pneumatic line can be discharged from the inlet port into the brake chamber.

During the pressure holding process, both the inlet valve and the release valve are closed. The relay valve piston moves down to the central position under the pressure of the control chamber. The piston in this position is not stable and will tend to change. At this time, the relay valve piston is in close contact with the plug, but the preload of the spring has not been overcome, the plug and the lower valve cover are also in close contact. Therefore, it hinders the gas inflow from the pneumatic line and the gas outflow from the brake chamber, and the compressed gas in the brake chamber cannot be discharged to maintain the brake pressure.

During pressure decreasing process, the release valve opens and the inlet valve closes. The piston of the relay valve stays at the initial position. At this time, the inlet port and the load chamber are separated by a plug, the load chamber is connected to the outlet port, the brake chamber is exhausted to the atmosphere, the pressure drops until it is balanced with the atmospheric pressure.

\subsection{Solenoid valve model}

In PEBS, as a high-speed switch valve, the solenoid valve's dynamic response characteristics directly affect the performance and working efficiency. In the working process of the solenoid valve, the parameters related to the movement of the spool mainly include voltage, current, inductance, spool displacement, etc. If the constant inductance value of the system is given, the delay time and switching characteristics of the solenoid valve are very little affected. Therefore, the modeling of the solenoid valve is carried out under the assumption that the inductance value changes very little. The relationship between the current and voltage in the coil is

$$
U=i R+L * d i / d t
$$

where $i, L, R$ and $U$ are the current, the inductance, the resistance of the electromagnetic coil and the voltage, respectively.
The specific calculation of the electromagnetic force is complicated, but there is a certain relationship between the electromagnetic force, the spool displacement and the current. Assumed that the calculation expression of the electromagnetic force as

$$
F_{\mathrm{e}}=f(i, x)
$$

where $F_{\mathrm{e}}$ and $x$ are the electromagnetic force and the spool displacement, respectively.

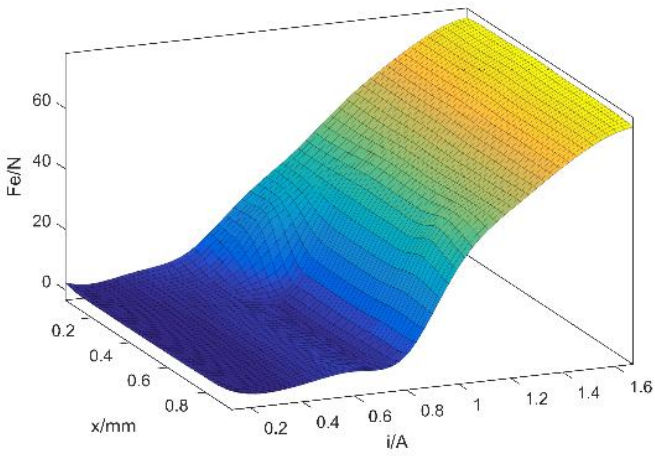

(a) Solenoid valve opening process

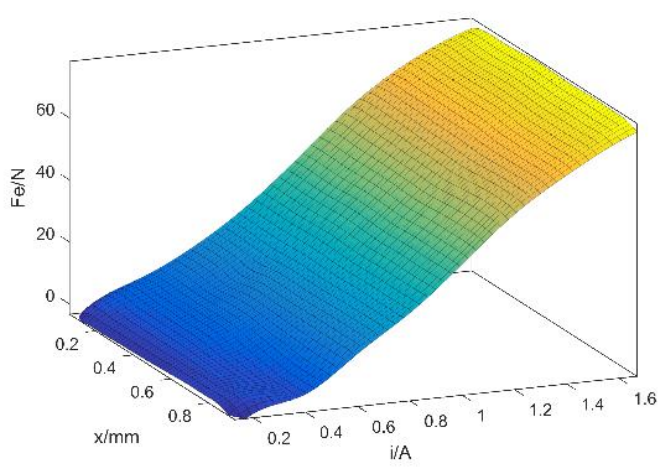

(b) Solenoid valve closing process

Figure 3 Three-dimensional curve between electromagnetic force, spool displacement and current

After establishing the physical model of the solenoid valve in Maxwell and setting the relevant parameters, the relationships between the electromagnetic force, spool displacement, current and time can be obtained. Fitting the obtained curve data through Matlab, the relationship among electromagnetic force, spool displacement and current is obtained as shown in Figure 3. The expression of the electromagnetic force fitted is

$$
F_{\mathrm{e}}=27.66 x^{2}+3.04 x i+8.74 x-4.27 i-4.47
$$

According to Newton's second law, the kinematic equation of the moving spool is

$$
m \ddot{x}=F_{\mathrm{e}}-p A_{0}-c \dot{x}-k\left(x+x_{\mathrm{p}}\right) \quad\left(0 \leq x \leq x_{\text {max }}\right)
$$


where $m, A_{0}, c$ and $x_{\mathrm{p}}$ are the mass of the moving spool, the effective area of the moving spool, the damping force and spring preload displacement, respectively.

\subsection{Dynamic modeling of PBWV}

According to the above analysis of the dynamic behaviour of PBWV braking process, the compressed air in the control chamber or brake chamber must produce enough force to drive the piston movement of the relay valve or brake chamber. In this process, the volume change equation of the control chamber and the load chamber is

$$
\begin{array}{cc}
V_{\mathrm{r}}=V_{\mathrm{r} 0}+A_{\mathrm{r}} x_{\mathrm{r}} & \left(0 \leq x_{\mathrm{r}} \leq x_{\mathrm{rt}}\right) \\
V_{\mathrm{c}}=V_{\mathrm{c} 0}+A_{\mathrm{c}} x_{\mathrm{c}}-A_{\mathrm{r}} x_{\mathrm{r}} & \left(0 \leq x_{\mathrm{r}} \leq x_{\mathrm{rt}}, 0 \leq x_{\mathrm{c}} \leq x_{\mathrm{ct}}\right)
\end{array}
$$

where, $V_{\mathrm{r}}, V_{\mathrm{r} 0}$ and $A_{\mathrm{r}}$ are the volume, the initial volume and the effective area in the control chamber, respectively, $V_{\mathrm{c}}, V_{\mathrm{c} 0}$ and $A_{\mathrm{c}}$ are the volume, the initial volume and the effective area in the load chamber, respectively, $x_{\mathrm{r}}$ and $x_{\mathrm{c}}$ are the displacement of the relay valve piston and the brake chamber piston, respectively; $x_{\mathrm{rt}}$ is the total piston displacement of the relay valve during inlet and release; $x_{\mathrm{ct}}$ is the piston displacement of the brake chamber.

According to Newton's second law, the kinematic equation of the piston in the relay valve and the brake chamber are respectively.

$\left\{\begin{array}{lr}m_{r} \ddot{x}_{\mathrm{r}}=A_{\mathrm{r}} p_{\mathrm{r}}-A_{\mathrm{r} 1} p_{\mathrm{c}}-F_{\mathrm{fr}} & \left(0 \leq x_{\mathrm{r}} \leq x_{\mathrm{rm}}\right) \\ \left(m_{\mathrm{r}}+m_{\mathrm{r} 1}\right) \ddot{x}_{\mathrm{r}}=A_{\mathrm{r}} p_{\mathrm{r}}-A_{\mathrm{r} 1} p_{\mathrm{c}}-K_{\mathrm{r}} x_{\mathrm{r}}-K_{\mathrm{r}} x_{\mathrm{or}}-F_{\mathrm{fr} 1} & \left(x_{\mathrm{rm}} \leq x_{\mathrm{r}} \leq x_{\mathrm{rt}}\right)\end{array}\right.$

$$
m_{\mathrm{c}} \ddot{x}_{\mathrm{c}}=A_{\mathrm{c}} p_{\mathrm{c}}-K_{\mathrm{c}} x_{\mathrm{oc}}-F_{\mathrm{fc}} \quad\left(0 \leq x_{\mathrm{c}} \leq x_{\mathrm{ct}}\right)
$$

where, $m_{\mathrm{r}}, m_{\mathrm{r} 1}$ and $m_{\mathrm{c}}$ are the mass of the relay valve piston, plug and the brake chamber piston respectively; $p_{\mathrm{r}}$ and $p_{\mathrm{c}}$ are the pressure in the control chamber and brake chamber respectively; $A_{\mathrm{r} 1}$ is the effective area of the load chamber; $F_{\mathrm{fr}}, F_{\mathrm{fr} 1}$ and $F_{\mathrm{fc}}$ are the friction between the piston of relay valve, plug, the piston of brake air chamber and the side; $x_{\mathrm{rm}}$ is the displacement of the piston during the release; $x_{\text {or }}$ and $x_{\text {oc }}$ are the pre-tension displacement of the relay valve spring and the brake chamber spring respectively; $K_{\mathrm{r}}$ and $K_{\mathrm{c}}$ are the spring stiffness of the relay valve spring and the brake chamber respectively.

Generally speaking, because braking is relatively fast and fierce, the variation of the air in the control chamber can be regarded as adiabatic. Assuming that the temperature difference between the gas entering the control chamber or the brake chamber and its original gas is ignored, the aerodynamic process within the system can be expressed as

$$
p(V / m)^{k}=p_{0}\left(V_{0} / m_{0}\right)^{k}=C
$$

where $p_{0}, V_{0}$ and $m_{0}$ are the pressure, volume and mass at the initial condition, respectively, and $p, V$ and $m$ are the corresponding states at equilibrium, $k$ is adiabatic exponent of gas, $C$ is proportional constant. Note: When the closed chamber is the control chamber or brake air chamber, the above parameters correspondingly change to $p_{\mathrm{r}}, V_{\mathrm{r}}, m_{\mathrm{r}}, p_{\mathrm{r} 0}, V_{\mathrm{r} 0}, m_{\mathrm{r} 0}$ or $p_{\mathrm{c}}, V_{\mathrm{c}}, m_{\mathrm{c}}, p_{\mathrm{c} 0}, V_{\mathrm{c} 0}, m_{\mathrm{c} 0}$. Differentiating Equation (9) with respect to time,

$$
\dot{p}=(k p / m) Q-(k p / V) \dot{V}
$$

where $Q=\dot{m}$ is the mass flow rate of gas in the closed chamber.

According to the formulation between the gas flow and orifice area it can be shown that

$Q= \begin{cases}c_{\mathrm{d}} p_{1} A \cdot\left(\frac{2}{k+1}\right)^{1 /(k-1)}\left(\frac{2 k}{T_{\mathrm{a}} \cdot R \cdot(k+1)}\right)^{1 / 2}, & \left(0 \leq p_{2} / p_{1}<0.528\right) \\ c_{\mathrm{d}} p_{1} A \cdot\left\{\frac{k \cdot\left[\left(p_{2} / p_{1}\right)^{2 / k}-\left(p_{2} / p_{1}\right)^{(k+1) / k}\right]}{T_{\mathrm{a}} \cdot R \cdot(k-1) / 2}\right\}^{1 / 2}, & \left(0.528 \leq p_{2} / p_{1} \leq 1\right)\end{cases}$

where $c_{\mathrm{d}}$ is the gas orifice flow coefficient, $p_{1}$ is the upstream air pressure, $p_{2}$ is the downstream air pressure, $A$ is the effective throttle area, $T_{\mathrm{a}}$ is the absolute temperature in the control chamber, $R$ is the specific gas constant, Constant 0.518 is a critical ratio of low-to-high pressure at the two sides of the orifice. When greater than 0.518, the flow is subsonic. Otherwise the flow is supersonic and the corresponding dynamics is complex which is oftentimes the case when air undergoes throttling.

Note: When the gas flows into the control chamber, $p_{1}=p_{\mathrm{s}}, p_{2}=p_{\mathrm{r}}$, when the gas flows out of the control chamber $p_{1}=p_{\mathrm{r}}, p_{2}=p_{\mathrm{a}}$, when the gas flows into the brake chamber $p_{1}=p_{\mathrm{s}}, p_{2}=p_{\mathrm{c}}$, when the gas flows out of the control chamber $p_{1}=p_{\mathrm{c}}, p_{2}=p_{\mathrm{a}}$. Where $p_{\mathrm{s}}$ is the pressure of supply air, $p_{\mathrm{a}}$ is the discharge atmospheric pressure.

\section{Controller Design}

The principle of MPC control is to solve the finite-time-domain open-loop optimization problem online at each sampling time according to the measurement information obtained at the current time, and then apply the first element of the solved control sequence to the 
controlled object. At the next sampling time, repeat the above process, refresh the optimization problem with new measurements and re-solve it. The process of the algorithm is mainly divided into three steps: predictive dynamic model, rolling optimization and feedback correction. Through rolling optimization and feedback correction, it has the advantages of good control effect and strong robustness, which can effectively overcome the uncertainty, nonlinearity and parallelism of the process.

According to the dynamic model created in the 2 section, it can be seen that the PEBS model is more complex and the system has strong-nonlinearity. When the MPC method is directly used to control the pressure of PEBS, because of the large amount of calculation, the result may not be calculated or the calculation speed is too slow. In order to improve the speed of MPC calculation for efficient control, this paper uses the accurate model to collect data and draw the MAP diagram, and directly uses the MAP diagram as the system dynamics model, which is used as the characteristic of a predictive control system. Because the control principle is consistent with that of MPC, the control algorithm is named analogous model predictive control (AMPC).

According to MPC theory, the model is modified or compensated in real time. However, for the sake of engineering reliability, the AMPC method is adopted when the error is large,so that the limit performance of the system can quickly approach the target. When the error is small, it is more appropriate to use proportional feedback continuous control. That is, a combination of AMPC and P control algorithm is used to control the pressure output. Schematic diagram of the PEBS pressure controller is shown in Figure 4.

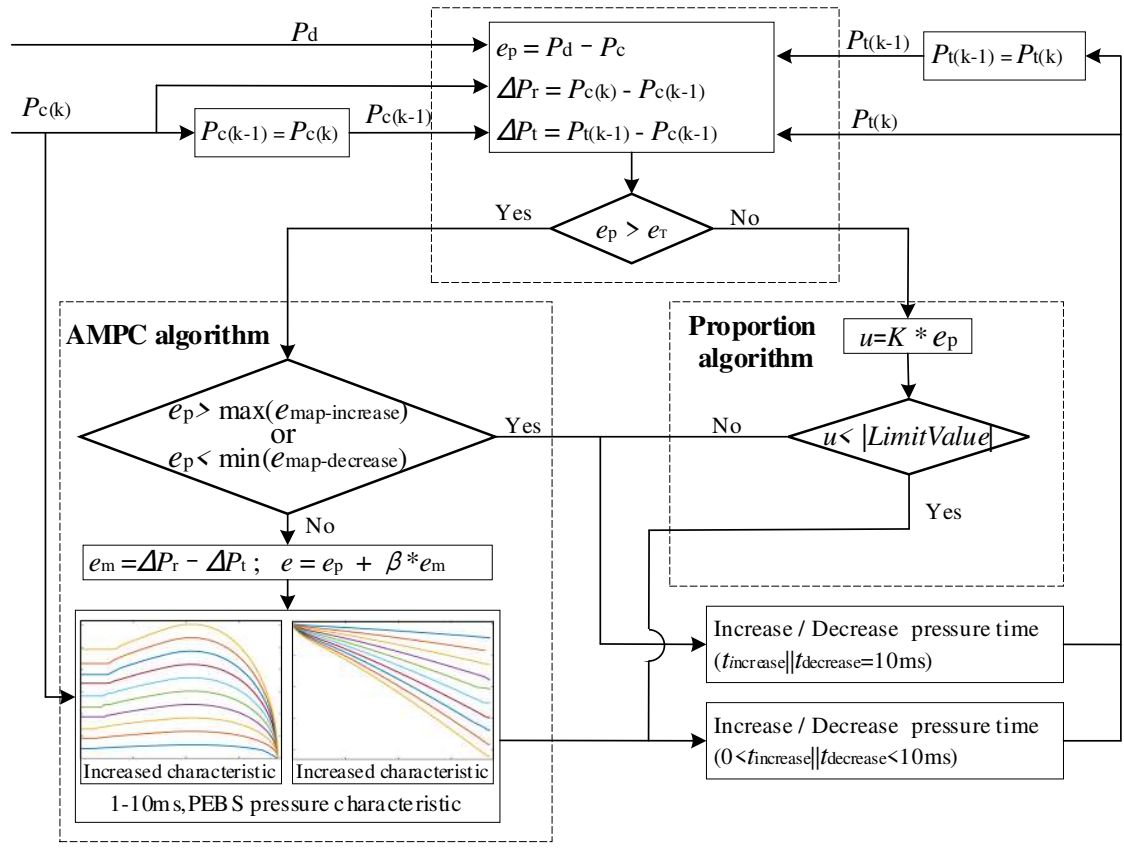

Figure 4 Schematic diagram of the PEBS pressure controller

As seen from Figure 4, When the error is large and exceeds the limit value $\left(e_{\mathrm{p}}>e_{\mathrm{T}}\right)$, the pressure output of PEBS is controlled by AMPC algorithm, on the contrary, it is controlled by proportional control algorithm. Where

$$
e_{\mathrm{p}}=p_{\mathrm{d}}-p_{\mathrm{c}}
$$

$p_{\mathrm{d}}$ and $p_{\mathrm{c}}$ are the target pressure and actual pressure of the brake chamber, respectively. $e_{\mathrm{T}}$ is the limit value of the decision selection control algorithm.

Aiming at the AMPC control algorithm, in order to improve the accuracy of the algorithm, the $\beta$ value is introduced to correct the error. The corrected error is expressed as

$$
e=e_{\mathrm{p}}+\beta e_{\mathrm{m}}
$$

where

$$
\begin{gathered}
e_{\mathrm{m}}=\Delta p_{\mathrm{r}}-\Delta p_{\mathrm{t}} \\
\Delta p_{\mathrm{r}}=p_{\mathrm{c}(\mathrm{k})}-p_{\mathrm{c}(\mathrm{k}-1)} \\
\Delta p_{\mathrm{t}}=p_{\mathrm{t}(\mathrm{k}-1)}-p_{\mathrm{c}(\mathrm{k}-1)}
\end{gathered}
$$

$p_{\mathrm{c}(\mathrm{k})}$ and $p_{\mathrm{c}(\mathrm{k}-1)}$ are the actual value of the current moment and the previous moment, respectively. $p_{\mathrm{t}(\mathrm{k}-1)}$ is the target pressure of the previous moment. 
According to the corrected error, the time of pressurization or decompression is found out based on the

$$
t_{\text {increase }} \| t_{\text {decrease }}= \begin{cases}10 & e_{\mathrm{p}}>\max \left(e_{\text {map-increase }}\right) \| e_{\mathrm{p}}<\min \left(e_{\text {map-decrease }}\right) \\ \text { Look up the MAP } & \max \left(e_{\text {map-increase }}\right)>e_{\mathrm{p}}>\min \left(e_{\text {map-decrease }}\right)\end{cases}
$$

where $t_{\text {increase }}$ and $t_{\text {decrease }}$ are the pressurization and decompression time, respectively. $e_{\text {map-increase }}$ and $e_{\text {map-decrease }}$ are the maximum and minimum pressure differences of pressurization and decompression in the MAP diagram.

According to the $\mathrm{P}$ control algorithm, the calculation equation of booster and decompression time is

$$
u=K * e_{\mathrm{p}}
$$

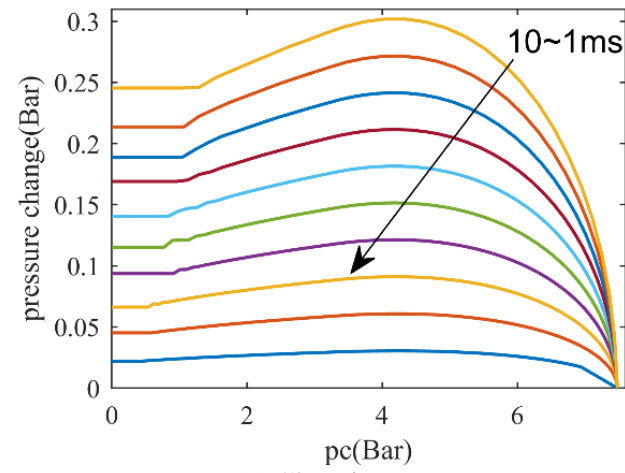

(a) Charging process

$$
t_{\text {increase }} \| t_{\text {decrease }}= \begin{cases}10 & u>\mid \text { LimitValue } \mid \\ 10 *(\mathrm{u} / \text { LimitValue }) & u>\mid \text { LimitValue } \mid\end{cases}
$$

where $K$ and LimitValue are proportional gain values and thresholds, respectively.

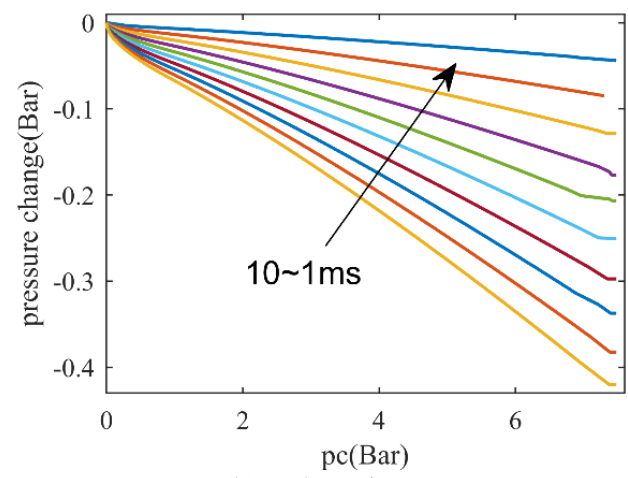

(b) Exhausting process

Figure 5 Increase / decrease pressure characteristics of brake chamber in 1-10ms

Figure 5 shows increase / decrease pressure characteristics of brake chamber in $1-10 \mathrm{~ms}$. It collects pressure data from the accurate model of the PEBS built above. Specific parameters are set to $7.5 \mathrm{bar}$ for air receiver pressure and the period is $0.5 \mathrm{~s}$, according to the control period $1-10 \mathrm{~ms}$, corresponding to the pressure data collected repeatedly when the waiting period is $499-490 \mathrm{~ms}$. then the collected pressure data are analysed and processed to obtain the relationship between pressure and pressure change during increase / decrease.

\section{PEBS model modification}

According to the AMPC control principle, because the MAP diagram is used to predict the characteristics of the system, its drawing comes from the accurate PEBS model, so it is necessary to modify the PEBS model created in section 2. It is concluded from the analysis that if the model can real-time and accurately reflect the dynamic parameters such as solenoid valve opening and closing time, gas flow coefficient, piston displacement of relay valve, control chamber pressure and brake chamber pressure in PBMV, the model can accurately describe the performance of the PEBS. Therefore, in this section, a variety of experimental devices are built to measure the dynamic parameters in real time and modify the model according to the experimental data. The schematic diagram of the experimental device is shown in Figure 6. 


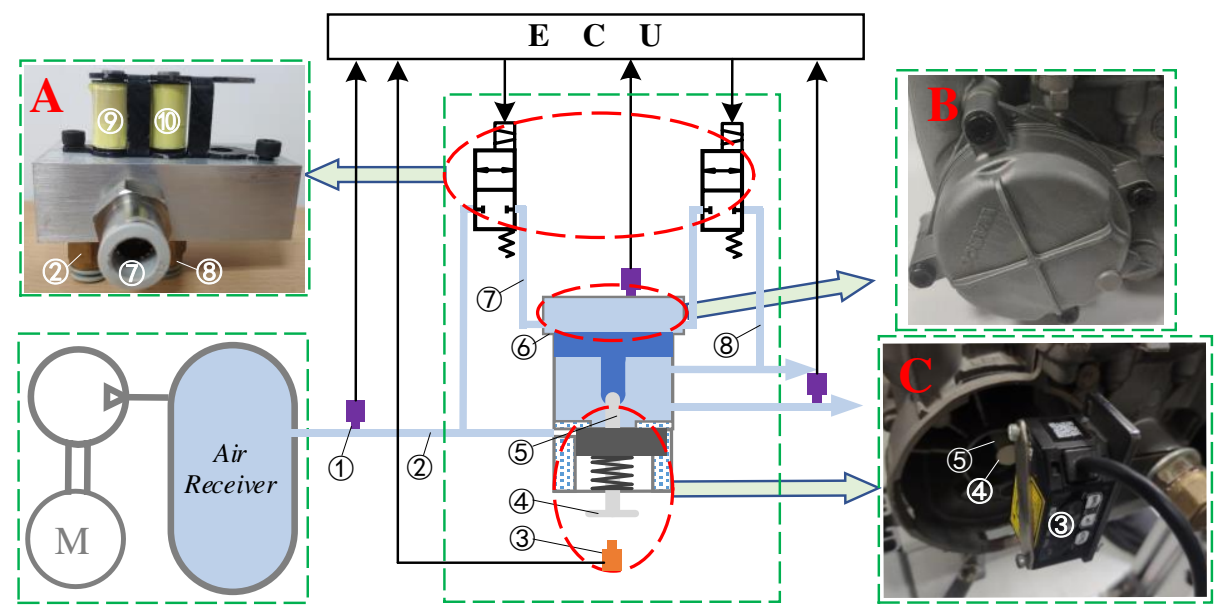

1.Pressure Sensor 2.Pneumatic Control Line 3.Laser Displacement Sensor 4.Circular Plate 5.Plastic Stick 6.New Valve Cover 7.Outlet Port 8.Exhaust Port 9.InleValve 10.Release Valve

Figure 6 Experimental schematic diagram of key parameter identification

\subsection{Determine the solenoid valve opening and closing time}

In order to better reflect the characteristics of the solenoid valve, it is necessary to know the delay time of the solenoid valve in the opening and closing section.

Fig 6A shows the principle of measuring the opening and closing time of solenoid valve. Among them, the internal flow passage of the valve block needs to meet the function of the inlet valve and release valve. According to the actual test, the relevant parameters of the solenoid valve are measured, including the number of turns of the coil, spring force, damping, coil resistance and so on. After setting the same parameters in Maxwell, the delay time of solenoid valve during opening and closing can be calculated.

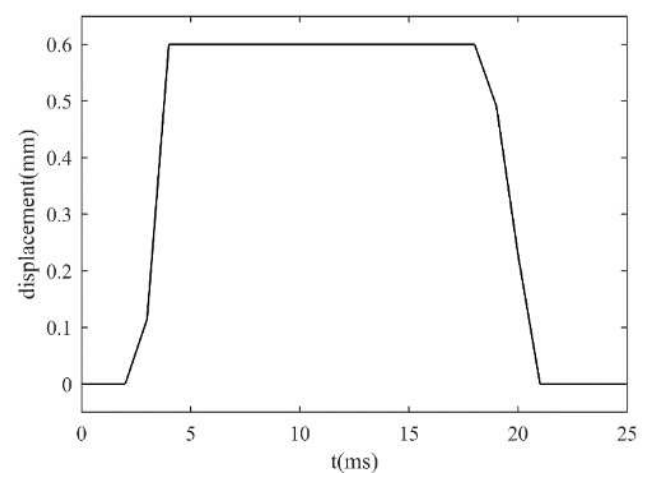

Figure 7 Opening and closing delay time of solenoid valve

Figure 7 shows the delay time when the solenoid valve is opened and closed. As can be seen from the figure, when the solenoid valve is opened and closed, the delay time is $2 \mathrm{~ms}$ and $8 \mathrm{~ms}$ respectively.

\subsection{Determine the gas flow coefficient}

Since the pressure of the control chamber cannot be measured directly, a new valve cover that can install a pressure sensor is redesigned to measure without destroying the performance of the valve. The measuring schematic diagram is shown in Figure 6B. The pressure of the brake chamber is measured directly by the pressure sensor.

According to equation (11), the gas flow coefficient is related to $c_{\mathrm{d}} 、 p_{1} 、 p_{2} 、 k 、 A 、 T_{\mathrm{a}}$ and $R$. In general, the value of $c_{\mathrm{d}}$ is uncertain and other values are determined, so the gas flow coefficient depends on $c_{\mathrm{d}}$. In order to modify $c_{\mathrm{d}}$ conveniently and quickly, this paper modifies the $c_{\mathrm{d}}$ directly according to the delay time and the increasing trend of the pressure data of the brake chamber.

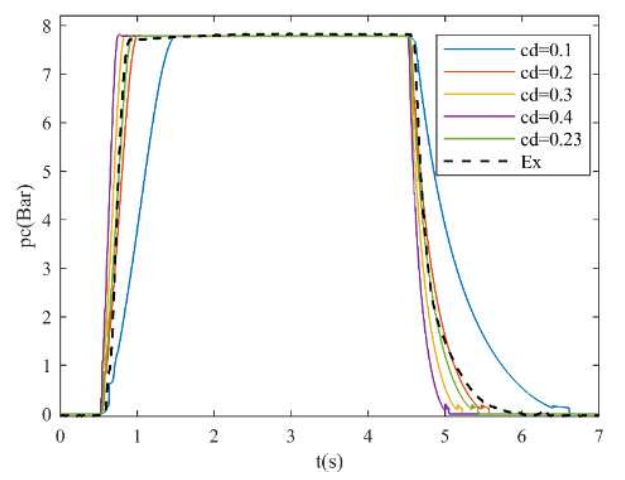

Figure 8 Comparison between actual pressure and calculated pressure in different $c_{\mathrm{d}}$

Figure 8 shows that the actual braking pressure is 
compared with the pressure calculated by different $c_{\mathrm{d}}$ in the model. From the analysis of the figure, it is found that when $c_{\mathrm{d}}=0.23$, the calculated braking pressure is closest to the actual pressure.

\subsection{Determine piston displacement of relay valve}

The piston of the relay valve controls the filling and outgassing of the whole valve, which is an important index that affects the performance of the whole valve. In order to meet the requirements of low cost, high measurement accuracy and simple operation when measuring the piston displacement in the valve, a fixed direct laser sensor bracket is designed based on the PBWV. Specifically, a light pillar is fixed by thread at the top of the piston, and a circular plate is placed at the other end of the pillar to ensure that the displacement of the piston is reflected by

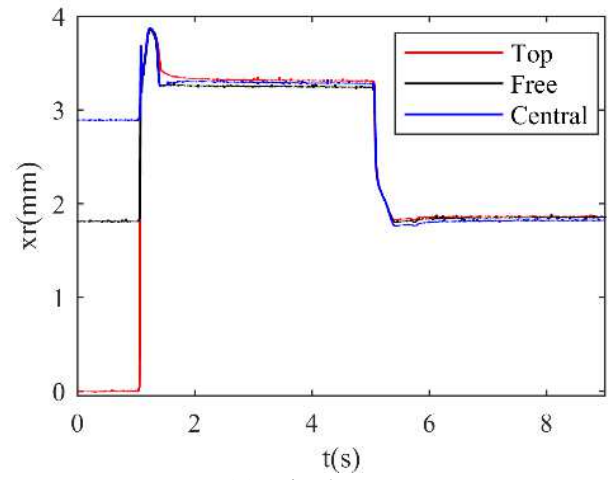

(a) Displacement

Figure 9 Comparison of different starting positions of relay valve pistons the displacement of the plate irradiated by laser. The measuring schematic diagram and the actual bench are shown in Figure 6C.

According to the working condition of PBWV, the piston displacement of relay valve is measured in three starting positions (top position, free position and central position). In the experiment, the pressure of the air receiver is controlled as $8 \mathrm{Bar}$, the input signal is constant for $0-1 \mathrm{~s}$, the pressure is pressurized for $1-5 \mathrm{~s}$, and the $5 \mathrm{~s}-9 \mathrm{~s}$ is decompressed. The data are collected and compared as shown in Figure 9. Figure 9(a) shows the displacement comparison of the piston in different initial positions, in which the piston is in the dynamic equilibrium position between $1.5 \mathrm{~s}$ and $5 \mathrm{~s}$, and Figure 9 (b) shows the corresponding pressure change of the brake chamber.

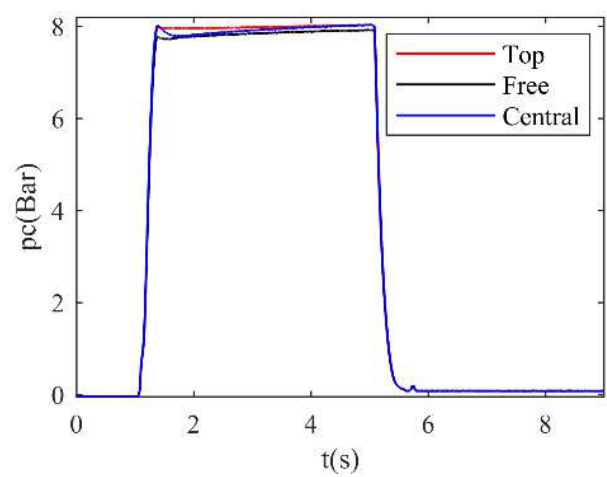

(b) Pressure
The analysis shows that no matter where the initial position of the piston is, the corresponding pressure change is consistent; when the piston starts at the top, the maximum displacement of the piston is $3.88 \mathrm{~mm}$; when the piston starts in the free position, the displacement is $1.5 \mathrm{~mm}$ until the piston is stable; when the piston starts in the central position, there is a dead zone from this position to the dynamic equilibrium position, and the dead zone displacement is $0.4 \mathrm{~mm}$.

\subsection{Model verification}

According to the above experimental equipment, a large number of data are measured and the relevant parameters in the model are modified. In this section, under the premise of the same parameters, the simulation and experiment of the PEBS are carried out respectively.

Table 1 The parameters used in solenoid valve

\begin{tabular}{cccccc}
\hline$R / \Omega$ & $L / \mathrm{H}$ & $m / \mathrm{kg}$ & $c /(\mathrm{N} * \mathrm{~m} / \mathrm{s})$ & $K /(\mathrm{N} / \mathrm{m})$ & $x_{\mathrm{p}} / \mathrm{m}$ \\
\hline 15 & 0.05 & 0.007 & 10 & 110 & $5 \mathrm{e}-3$ \\
\hline
\end{tabular}

Table 2 The parameters used in the system

\begin{tabular}{cccc}
\hline Parameters & Values & Parameters & Values \\
\hline$p_{\mathrm{s}} / \mathrm{Pa}$ & $8 \mathrm{e} 5$ & $m_{\mathrm{r}} / \mathrm{kg}$ & 0.046 \\
$p_{\mathrm{a}} / \mathrm{Pa}$ & $1 \mathrm{e} 5$ & $m_{\mathrm{r} 1} / \mathrm{kg}$ & $5 \mathrm{e}-4$ \\
$T_{\mathrm{a}} / \mathrm{K}$ & 300 & $p_{\mathrm{r} 0} / \mathrm{Pa}$ & $1 \mathrm{e} 5$ \\
$c_{\mathrm{d}}$ & 0.23 & $V_{\mathrm{r} 0} /\left(\mathrm{m}^{\wedge} 3\right)$ & $2.2 \mathrm{e}-5$ \\
$R /\left(\mathrm{J} /\left(\mathrm{kg}^{*} \mathrm{~K}\right)\right)$ & 287.1 & $A_{\mathrm{r}} /\left(\mathrm{m}^{\wedge} 2\right)$ & $3.2 \mathrm{e}-3$ \\
$k$ & 1.4 & $A_{\mathrm{r} 1} /\left(\mathrm{m}^{\wedge} 2\right)$ & $3.1 \mathrm{e}-3$ \\
$x_{\mathrm{ri}} / \mathrm{m}$ & 0 & $K_{\mathrm{r}} /(\mathrm{N} / \mathrm{m})$ & 2500 \\
$x_{\mathrm{rm}} / \mathrm{m}$ & $1.5 \mathrm{e}-3$ & $x_{0 \mathrm{r}} / \mathrm{m}$ & 0.02175 \\
$x_{\mathrm{rr}} / \mathrm{m}$ & $3.88 \mathrm{e}-3$ & $m_{\mathrm{c}} / \mathrm{kg}$ & 0.65 \\
$p_{\mathrm{c} 0} / \mathrm{Pa}$ & $1 \mathrm{e} 5$ & $V_{\mathrm{c} 0} / \mathrm{m}$ & $7.5 \mathrm{e}-5$ \\
$A_{\mathrm{c}} /\left(\mathrm{m}^{\wedge} 2\right)$ & $9.5 \mathrm{e}-3$ & $K_{\mathrm{c}} /(\mathrm{N} / \mathrm{m})$ & 2150 \\
$x_{0 \mathrm{c}} / \mathrm{m}$ & 0.055 & $x_{\mathrm{c} i} / \mathrm{m}$ & 0 \\
$x_{\mathrm{c}} / \mathrm{m}$ & 0.012 & & \\
\hline
\end{tabular}

Figure 10 shows the comparison between simulation and experimental data when the air receiver pressure is set to 2bar, 4bar, 6bar, 7.8bar. The analysis shows that the simulation data are basically consistent with the experimental data. 


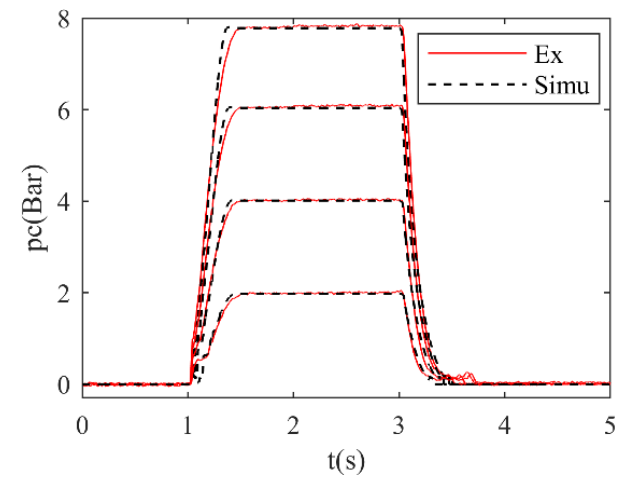

Figure 10 Static verification

Figure 11 shows brake chamber pressure data between simulation and experiment based on $\mathrm{P}$ control. The pressure of the air source is controlled to $7 \mathrm{bar}$, and the expected pressure is set to step waveform, triangular waveform and sinusoidal waveform. The analysis shows that the simulation data are basically consistent with the experimental data.

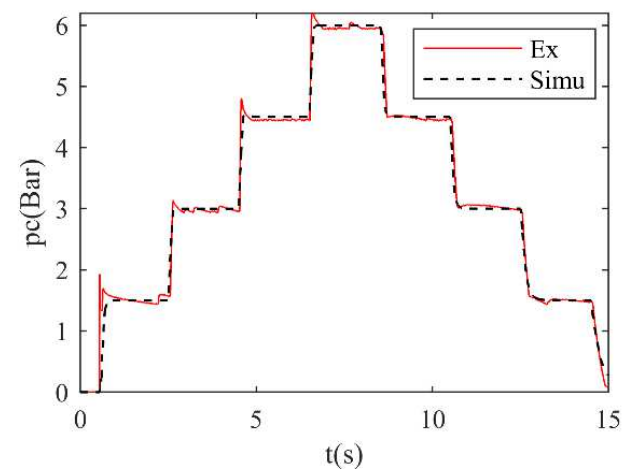

(a) Step response

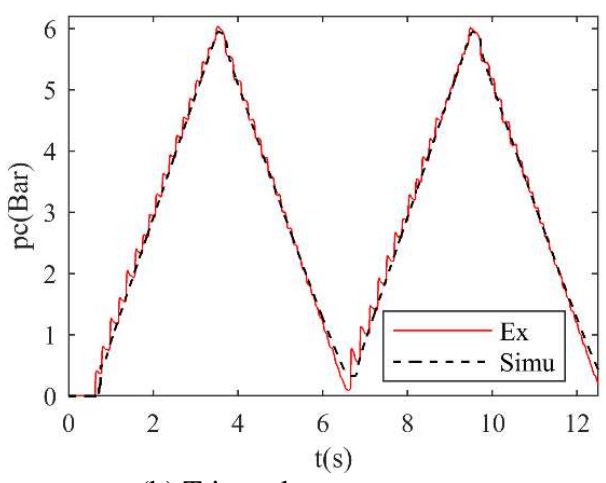

(b) Triangular wave response

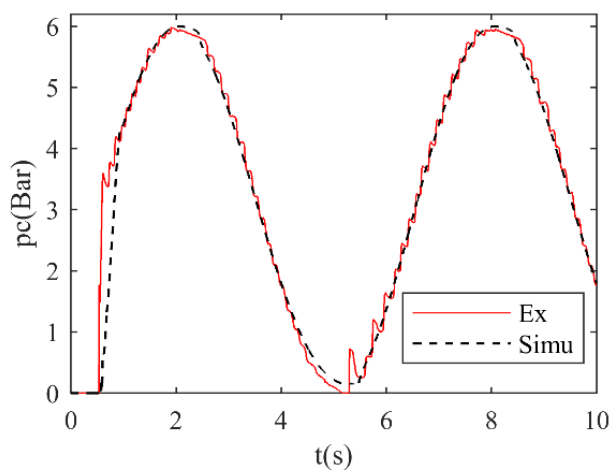

(c) Sin response

Figure 11 Dynamic verification

Comprehensive analysis shows that the above model can accurately reflect the characteristics of the PEBS and can provide guidance for the analysis of its performance.

\section{Experiments and Results}
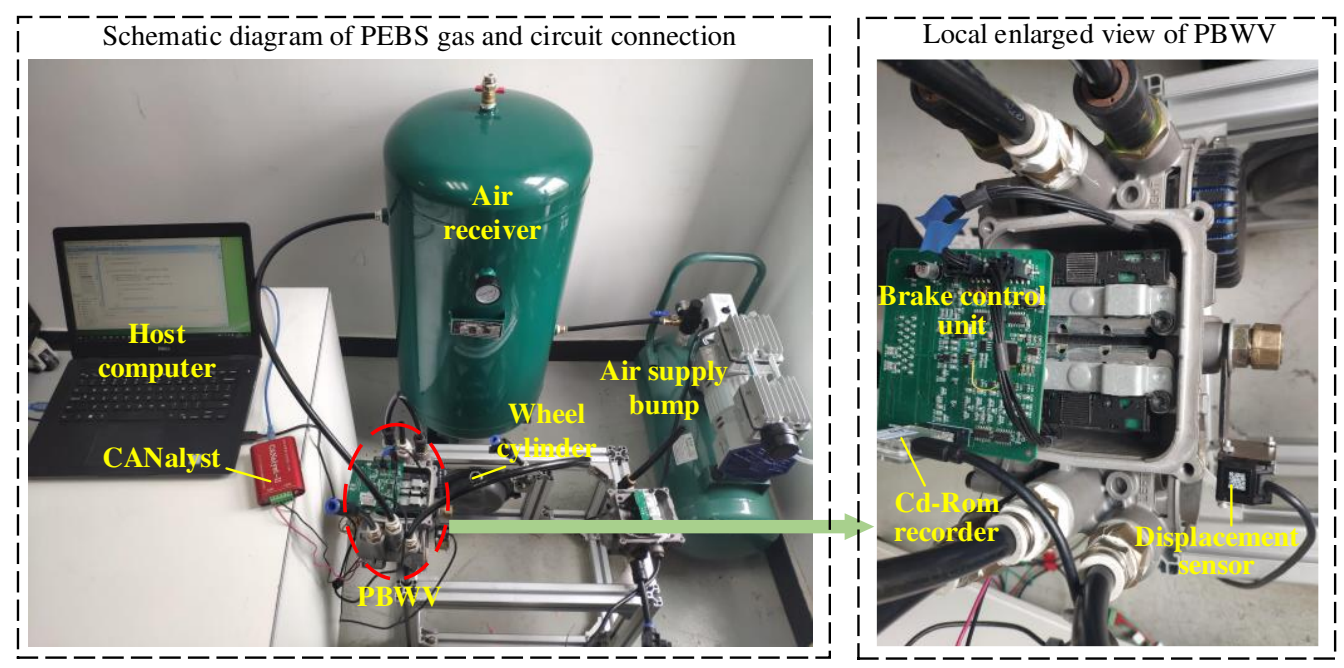

Figure 12 PEBS test bench 
Figure 12 shows the indoor test bench built to validate the controller design. The brake chamber pressure is obtained through the pressure sensor embedded in the PBWV of commercial vehicles. The controller chip is SPC5 series automotive 32-bit micro-control chip designed by ST Co., which provides multi-channel IO ports, AD analog signal acquisition, PWM input and output and CAN communication. The function configuration and the writing of the underlying code are completed by the SPC5 series special development software SPC5 Studio, and the online debugging is carried out by the supporting debugging software UDE STK. In the process of on-line debugging, the expected pressure, actual pressure and other information are transmitted to the host computer through the CANalyst to realize CAN communication. The real-time tracking control and parameter adjustment of a pressure curve are carried out through the Matlab software in the host computer, so that the pressure control experiment can be carried out efficiently.

Based on the existing situation, this paper controls the pressure output of the PEBS under different air receiver pressure. Figure 13 shows that under different expected pressures, the pressure output of PEBS is controlled by simple proportional control algorithm by changing the pressure of air source.

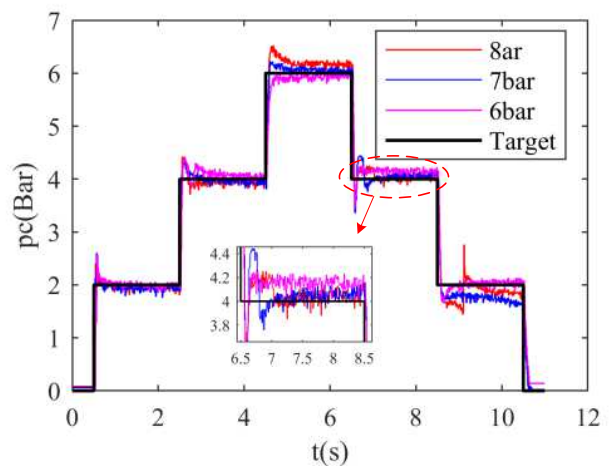

(a)Step response

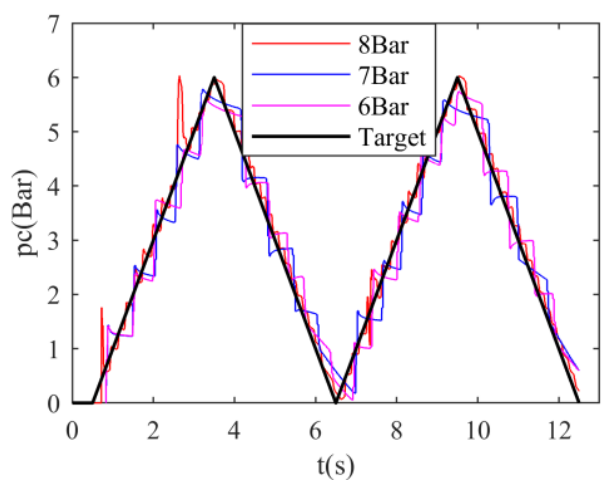

(b) Triangular wave response

Figure 13 Experimental results under the proportional control
The analysis shows that if an air source pressure is set and the proportional control parameters are adjusted, the valve pressure can be effectively controlled, but there will be local jitter under other air receiver pressure. In addition, the $\mathrm{P}$ control algorithm can control the error within $20 \mathrm{Kpa}$.

Figure 14 shows the real-time control of the valve by using the control logic of AMPC and proportional control on the basis of the same conditions as proportional control. From the control results, the actual pressure can well follow the step and triangle wave target pressure within the error is $8 \mathrm{KPa}$, so it is verified that the combination of AMPC and proportional control algorithm proposed in this paper can well regulate and control the target pressure under different air receiver pressure.

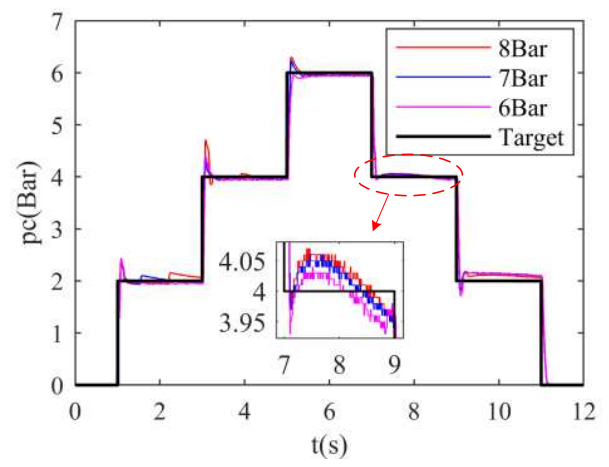

(a)Step response

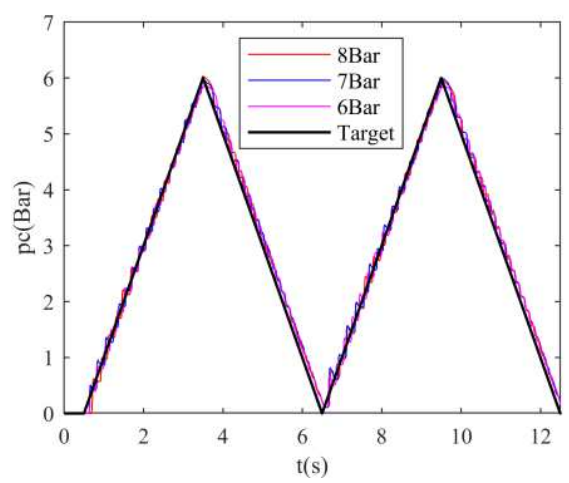

(b) Triangular wave response

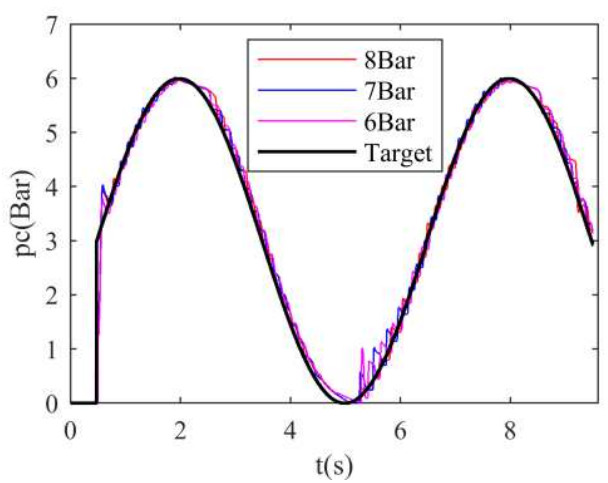

(c) Sin wave response 
Figure 14 Experimental results under the AMPC and proportional control

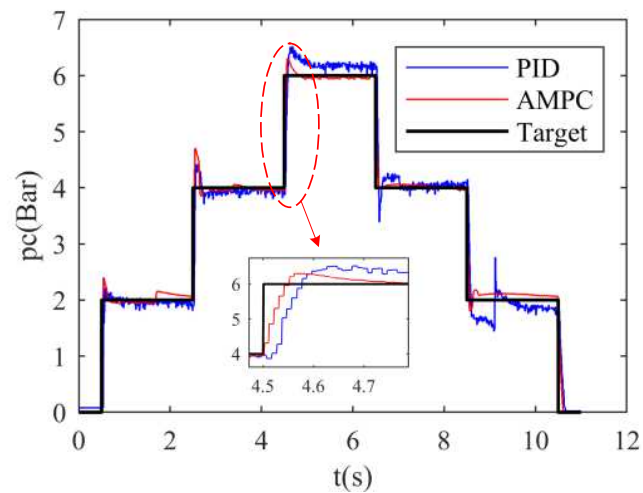

(a)Step response

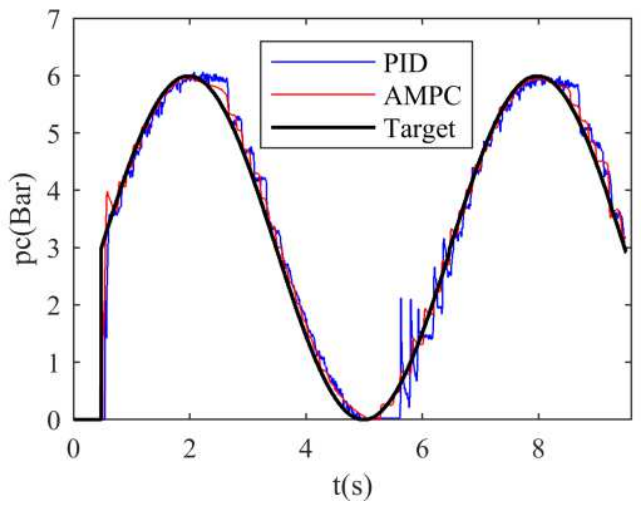

(b) Sin wave response

Figure 15 Comparison of response time between $\mathrm{P}$ and AMPC control algorithms

Figure 15 shows that under the same conditions, the $\mathrm{P}$ control algorithm and the AMPC control algorithm are used to control the PBWV, and the response time is $77 \mathrm{~ms}$ and $52 \mathrm{~ms}$ respectively, that is, the rapidity of the new algorithm is $32.5 \%$ higher than that of the traditional algorithm.

\section{Conclusions}

In this paper, according to several experimental measuring devices of dynamic parameters, the accurate model of PEBS is determined by real-time measurement and correction of parameters. The accuracy of the model is verified by comparing the simulation and experimental data. and the dynamic model of PEBS can accurately reflect its pressure characteristics. In addition, based on the accurate model, a logic threshold control scheme based on the combination of AMPC control and feedback control is proposed for the time-varying parameters of the system. The experimental results show that under different air source pressures, the designed controller can stably control the pressure output of PEBS and ensure that the error is within $8 \mathrm{KPa}$ and the rapidity is improved by $32.5 \%$.

\section{Declaration}

\section{Acknowledgements}

Not applicable

\section{Funding}

Supported by the State Key Laboratory of Automotive Safety and Energy (Grant No. KF2006), the National Science Foundation of China (Grant No. 51905293), the Postdoctoral Science Foundation of China (Grant No.2019M660621), the Golden Bridge Seed Foundation of Beijing Association for Science and Technology (Grant No. ZZ19034).

\section{Availability of data and materials}

The datasets supporting the conclusions of this article are included within the article.

\section{Authors' contributions}

The author' contributions are as follows: $\mathrm{XW}$ and $\mathrm{YY}$ were in charge of the whole trial; YZ wrote the manuscript; $\mathrm{XT}$ assisted with sampling and laboratory analyses. All authors read and approved the final manuscript.

\section{Competing interests}

The authors declare no competing financial interests.

\section{Consent for publication}

Not applicable

\section{Ethics approval and consent to participate}

Not applicable

\section{References}

[1] K Hussain, W Stein, A J Day. Modelling commercial vehicle handling and rolling stability. Proceedings of the Institution of Mechanical Engineers, Part K: Journal of Multi-body Dynamics, 2005, 219(4): 357-369.

[2] G Morrison, D Cebon. Combined emergency braking and turning of articulated heavy vehicles. Vehicle System Dynamics, 2017, 55(5): 725-749.

[3] G Morrison, D Cebon. Sideslip estimation for articulated heavy vehicles at the limits of adhesion. Vehicle System Dynamics, 2016, 54(11):1601-1628.

[4] J Wu, X Wang, L Li, et al. Hierarchical control strategy with battery aging consideration for hybrid electric vehicle regenerative braking control. Energy, 2018, 145: 301-312.

[5] F Ning, Y Shi, M Cai, et al. Research progress of related technologies of electric-pneumatic pressure proportional valves. Applied Sciences, 2017, 7(10): 1074-1089.

[6] S Lambeck, C Busch. Exact Linearization Control for a pneumatic proportional pressure control valve. In Proceedings of the IEEE 
International Conference on Control and Automation, 2010: 22-27.

[7] E E Topçu, İ Yüksel, Z Kamış. Development of electro-pneumatic fast switching valve and investigation of its characteristics. Mechatronics, 2006, 16(6): 365-378.

[8] M You, J Zhang, D Sun, et al. Characteristics analysis and control study of a pneumatic proportional valve. IEEE Advanced Information Technology Electronic and Automation Control Conference, 2015: 242-247.

[9] Z S Wang, G Y Li, Q Q Wu, et al. Research on pressure characteristics of vehicle air braking system with leakage from pipeline. Applied Mechanics and Materials, 2012, 157:608-611.

[10]S Bharath, B C Nakra, K N Gupta. Mathematical model of a railway pneumatic brake system with varying cylinder capacity effects. Journal of Dynamic Systems, Measurement and Control, 1990, 112: 456-462.

[11]Z Wang, X Zhou, C Yang, et al. An Experimental Study on Hysteresis Characteristics of a Pneumatic Braking System for a Multi-Axle Heavy Vehicle in Emergency Braking Situations. Applied Sciences, 2017, 7:799-815.

[12]M Pipan, N Herakovic. Closed-loop volume flow control algorithm for fast switching pneumatic valves with PWM signal. Control Engineering Practice, 2018, 70: 114-120.

[13]X H Wu, L Li, X Y Wang, et al. Nonlinear controller design and testing for chatter suppression in an electric-pneumatic braking system with parametric variation. Mechanical Systems and Signal Processing, 2020, 135: 106401.

[14]M Dousti, S Ç Başlamışlı. Experimental validation and robusness analysis of a multiple model switching antilock braking system control algorithm. International Journal of Vehicle Design, 2016, 71(1/2/3/4), 226-257.

[15]S Hodgson, M Tavakoli, M T Pham, et al. Nonlinear discontinuous dynamics averaging and PWM-based sliding control of solenoid-valve pneumatic actuators. IEEE/ASMETransactions on Mechatronics, 2015, 20(2): 876-888.

[16]J I Miller, D Cebon. A high-performance pneumatic braking system for heavy vehicles. Vehicle System Dynamics, 2010, 48(S1): 373-392.

[17]S Palanivelu, J Patil, A K Jindal. Modeling and optimization of pneumatic brake system for commercial vehicles by model based design approach. SAE Technical Paper, 2017.

[18]X Kong, J Zhang, T Li, et al. Research on Linear Pressure Control of Force Control System of High-speed Switch Solenoid Valve. Journal of Mechanical Engineering, 2014, 50:192-199.

[19]P Falconea, H E Tsengb, F Borrellic, et al. MPC-based yaw and lateral stabilization via active front steering and braking. Vehicle System Dynamics, 2009, 46: 611-628.

[20]S H Lee, Y O Lee, B A Kim, et al. Proximate model predictive control strategy for autonomous vehicle lateral control. IEEE American Control Conference (ACC), 2012,3605-3610.

[21]Y G Xi. Predictive Control. Beijing: National Defense Industry Press, 1991.

[22]I Schepers, D Schmitz, D Weiler, et al. A novel model for optimized development and application of switching valves in closed loop control. International Journal of Fluid Power, 2011, 12(3): 31-40.

[23]R Kern. Physical modelling of a long pneumatic transmission line: models of successively decreasing complexity and their experimental validation. Mathematical and Computer Modelling of Dynamical Systems, 2017, 23(5): 536-553.

[24]W Wei, Y Hu, Q Wu, et al. An air brake model for longitudinal train dynamics studies. Vehicle System Dynamics, 2017, 55(4): 517-533.
[25]S C Subramanian, S Darbha, K R Rajagopal. Modeling the Pneumatic Subsystem of an S-cam Air Brake System. Transactions-American society of Mechanical Engineers Journal of Dynamic Systems, Measurement and Control, 2004, 126(1):36-46.

[26]H Zhou, Z Liu, X Yang, et al. Vehicle parameters identification with particle swarm optimisation for four wheel independent motor-drive vehicle. International Journal of Vehicle Design, 2019, 79(2-3): 127-142.

[27]Y Luo, K Cao, L Xie, et al. Coordinated fault tolerant control of over-actuated electric vehicles based on optimal tyre force distribution. International Journal of Vehicle Design, 2017, 75(1/2/3/4), 47-74.

[28]H Zheng, S Ma, Y Liu. Vehicle braking force distribution with electronic pneumatic braking and hierarchical structure for commercial vehicle. Proceedings of the Institution of Mechanical Engineers, Part I: Journal of Systems and Control Engineering, 2018, 232(4):481-493.

\section{Biographical notes}

Yong-Tao Zhao, born in 1991, is currently a $\mathrm{PhD}$ candidate at School of Engineering and Technology, China University of Geosciences (Beijing), China. He received his bachelor degree from Anhui Polytechnic University, China, in 2019. His research interests include electrical mechanical system design and vehicle dynamics.

E-mail: 3002190022@cugb.edu.cn

Yi-Yong Yang, born in 1966, is currently an professor at China University of Geosciences (Beijing), China. He received his $\mathrm{PhD}$ degree from Tsinghua University, China, in 2004. His research interests include vehicle dynamic, mechanical dynamics and control.

E-mail: yangyy@cugb.edu.cn

Xiu-Heng Wu, born in 1990, is currently an associate professor at China Agricultural University, China. He received his $\mathrm{PhD}$ degree from China Agricultural University, China, in 2018. His research interests include vehicle dynamics control, design and control of electric braking system, nonlinear time-frequency analysis and control.

E-mail: wxh599@cau.edu.cn

Xing-Jun Tao, born in 1993, is currently a master candidate at China University of Geosciences(BeiJing), China.

E-mail: 1689735300@qq.com 
Figures

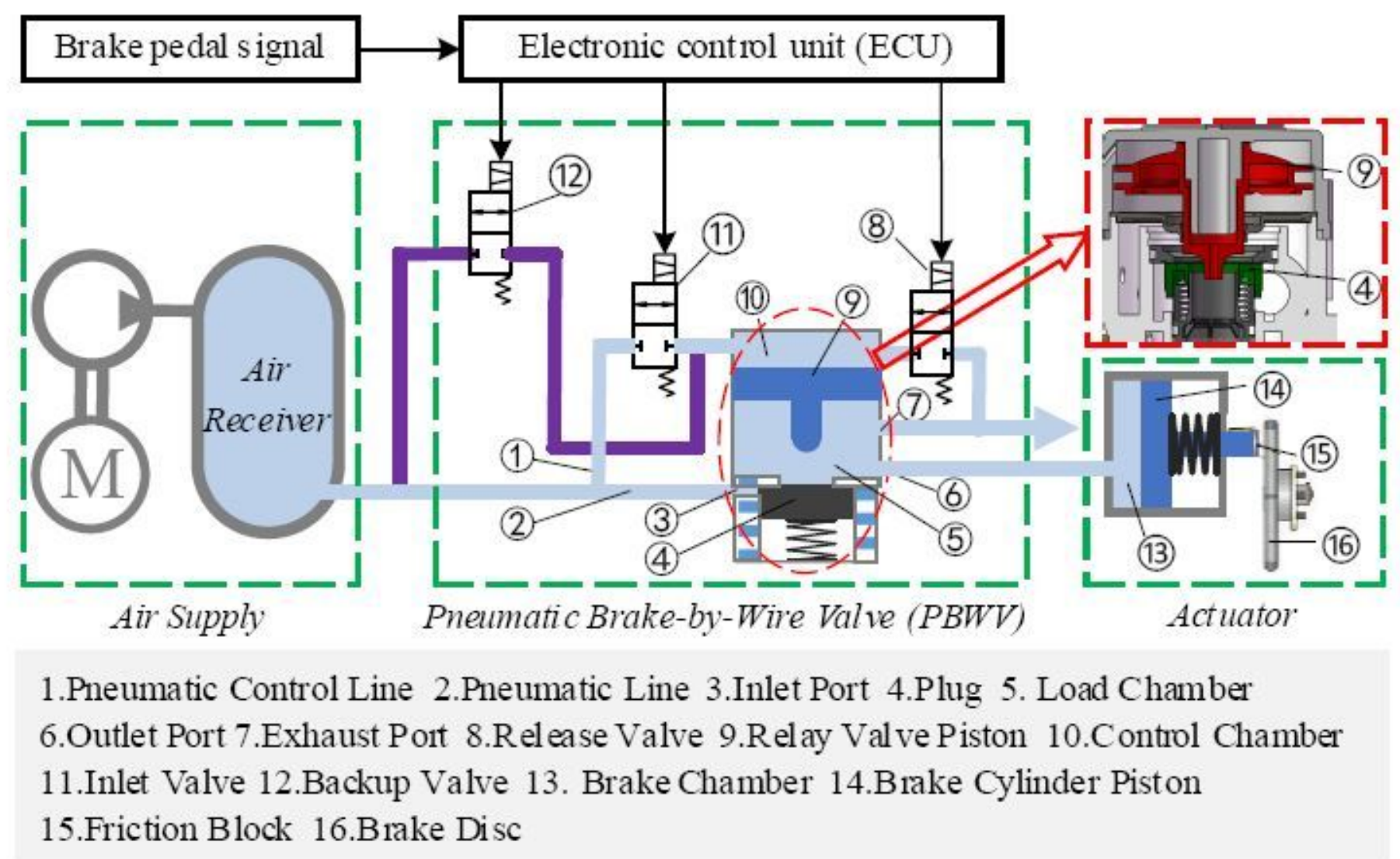

Figure 1

Schematic diagram of Pneumatic Electric Braking System 


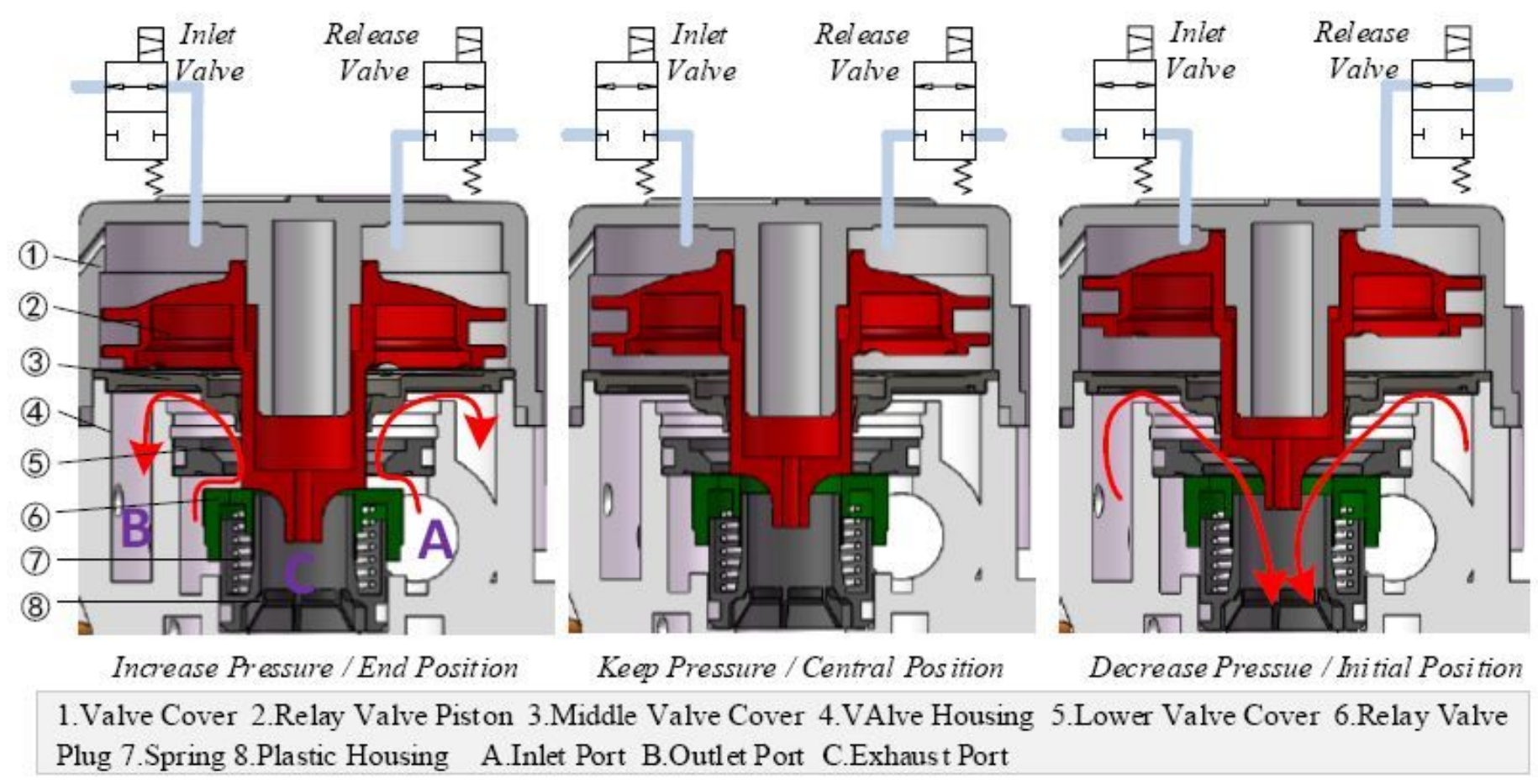

Figure 2

Relay valve piston position and corresponding working state 


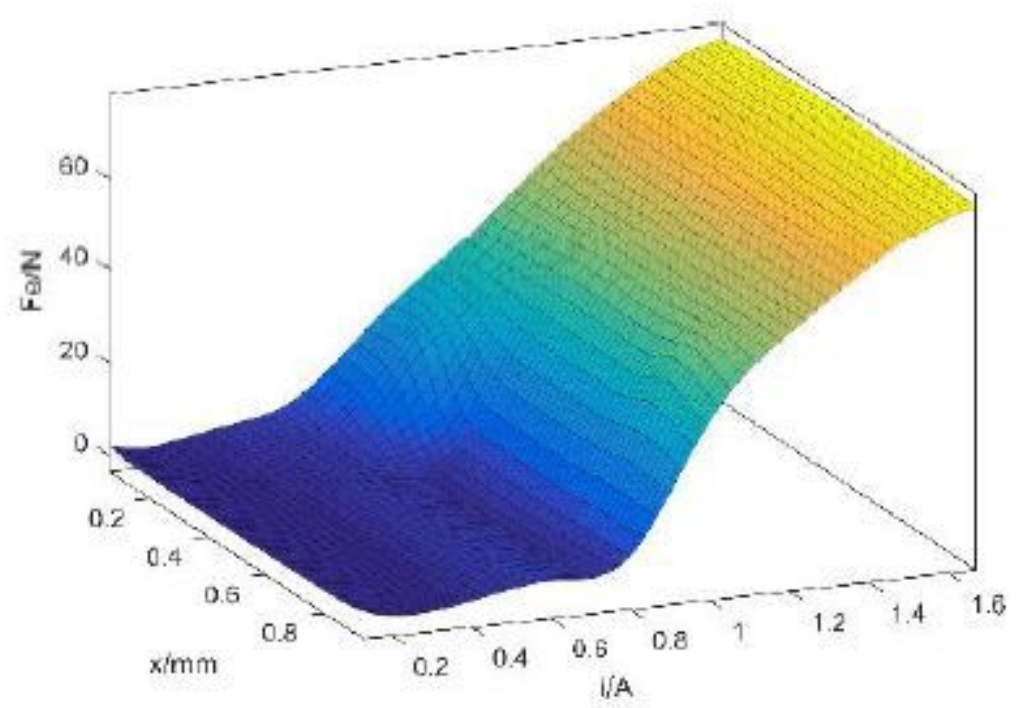

(a) Solenoid valve opening process

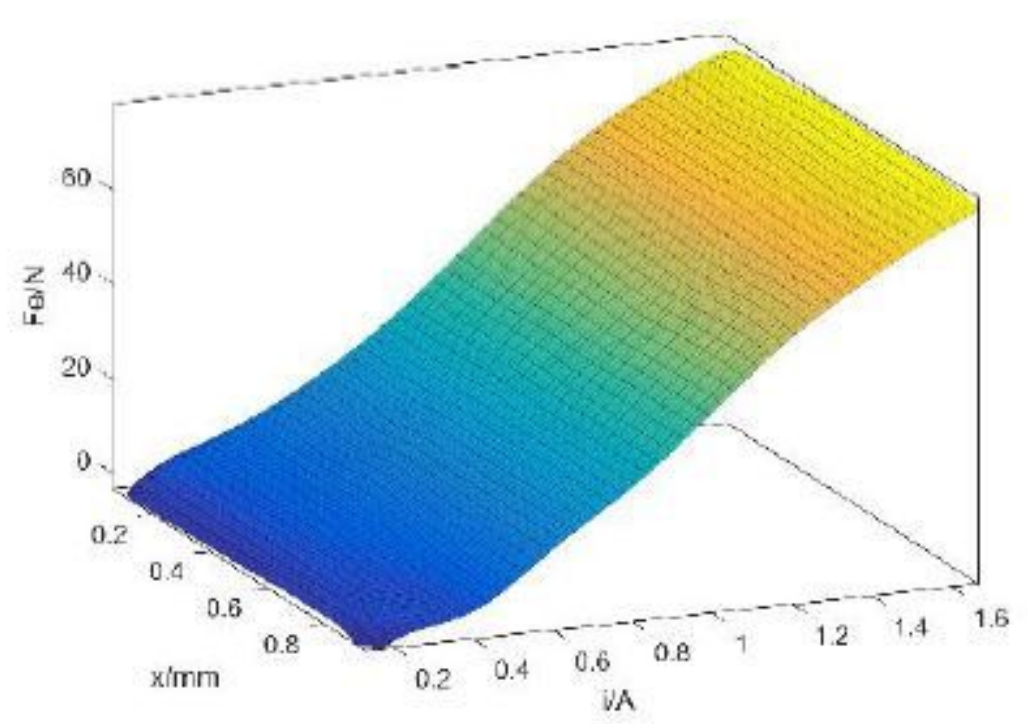

(b) Solenoid valve closing process

\section{Figure 3}

Three-dimensional curve between electromagnetic force, spool displacement and current 


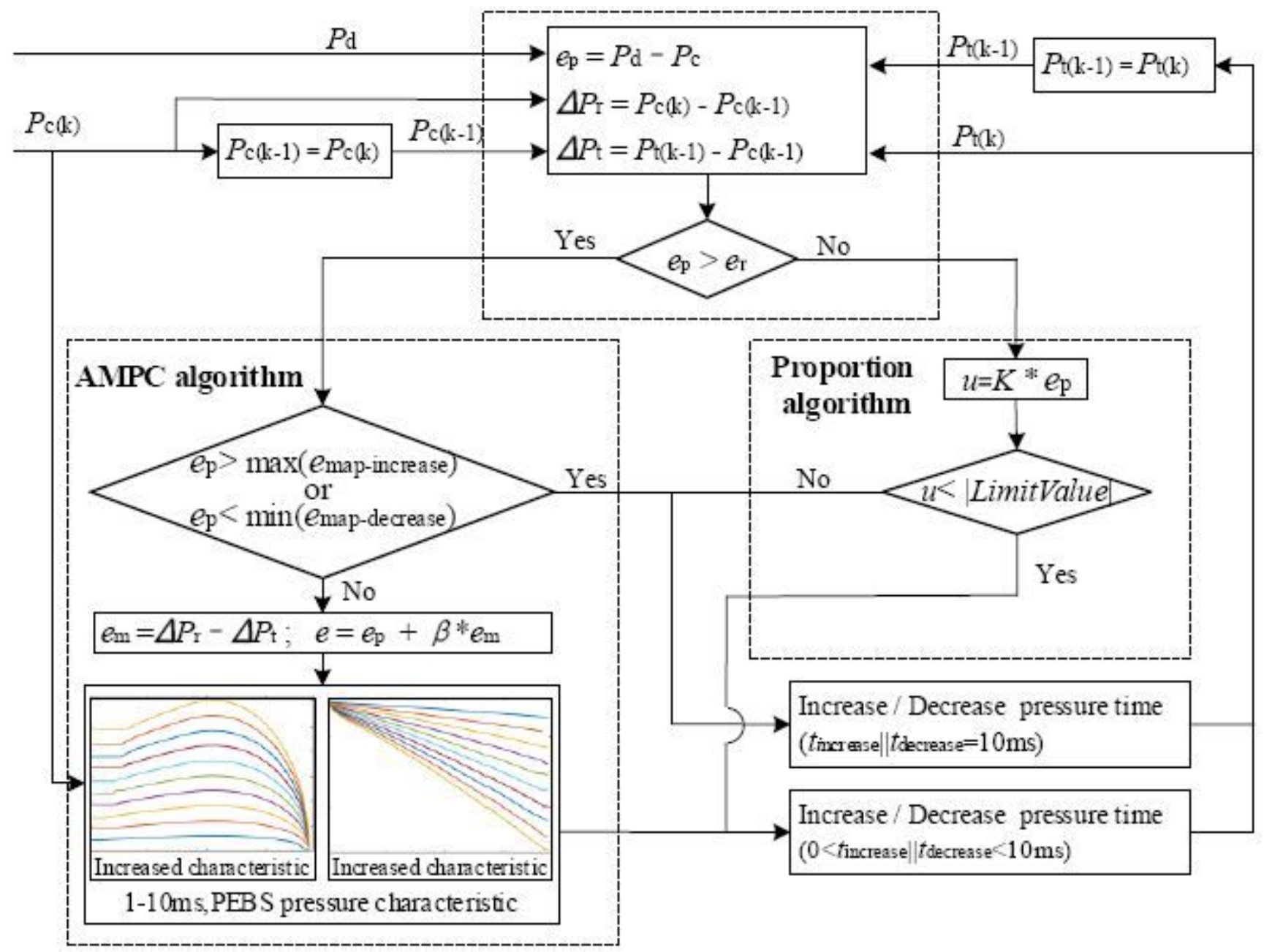

Figure 4

Schematic diagram of the PEBS pressure controller

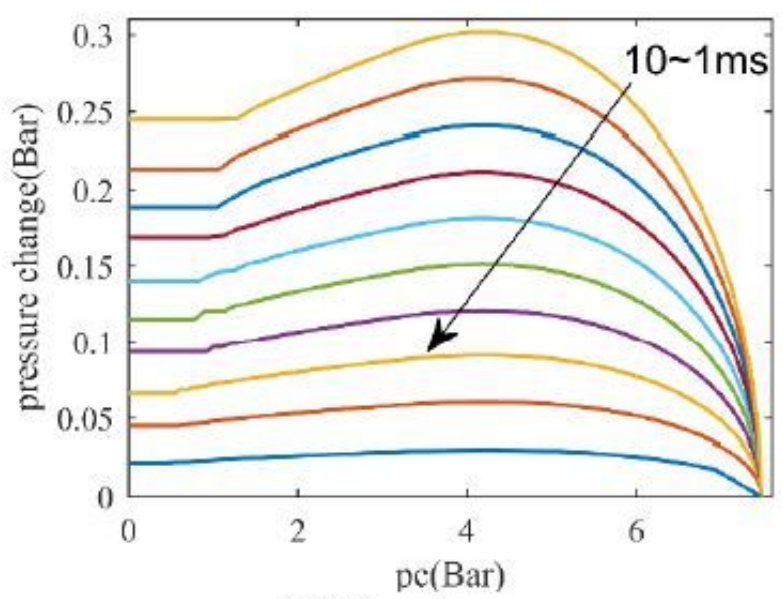

(a) Charging process

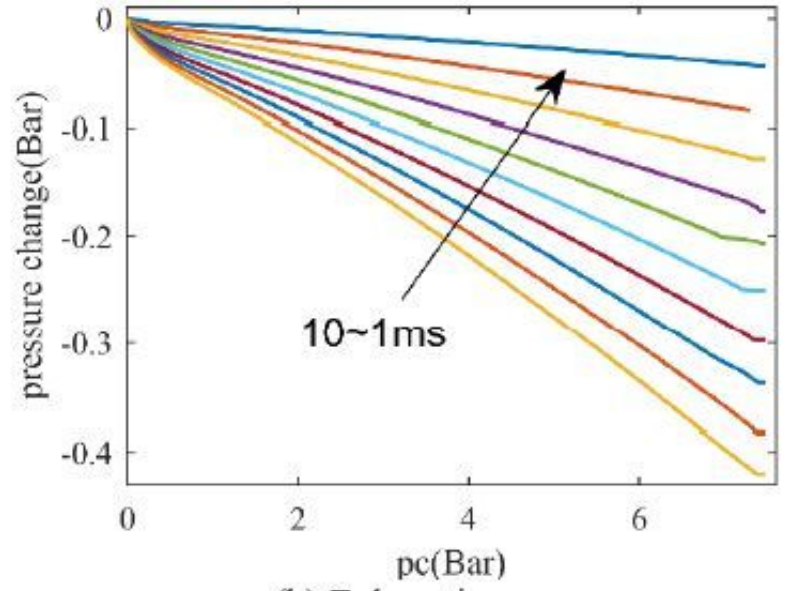

(b) Exhausting process

Figure 5

Increase / Decrease pressure characteristics of brake chamber in 1-10ms 


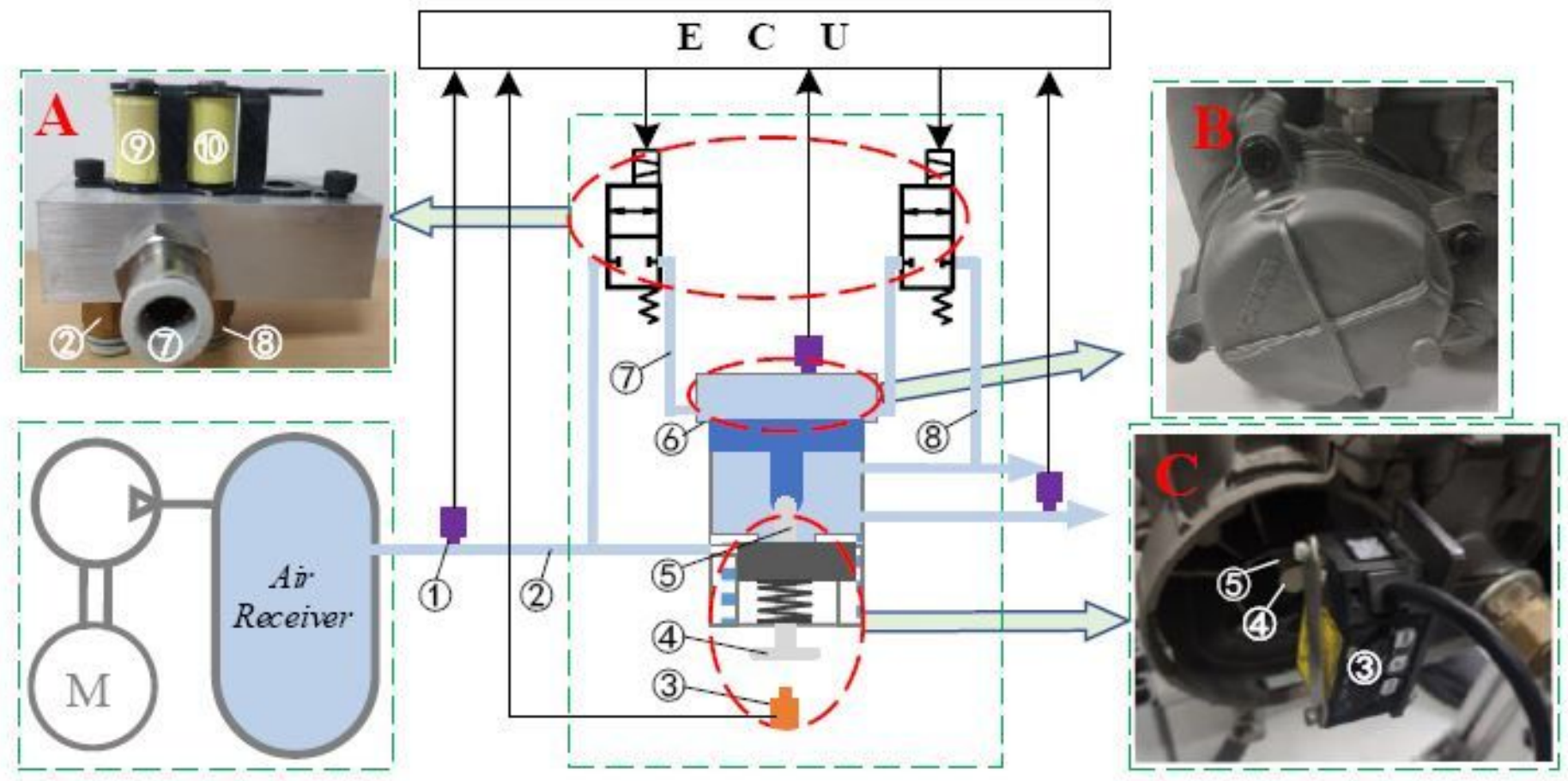

1.Pressure Sensor 2.Pneumatic Control Line 3.Laser Displacement Sensor 4.Circular Plate 5.Plastic Stick 6.New Valve Cover 7.Outlet Port 8.Exhaust Port 9.InleValve 10.Release Valve

\section{Figure 6}

Experimental schematic diagram of key parameter identification

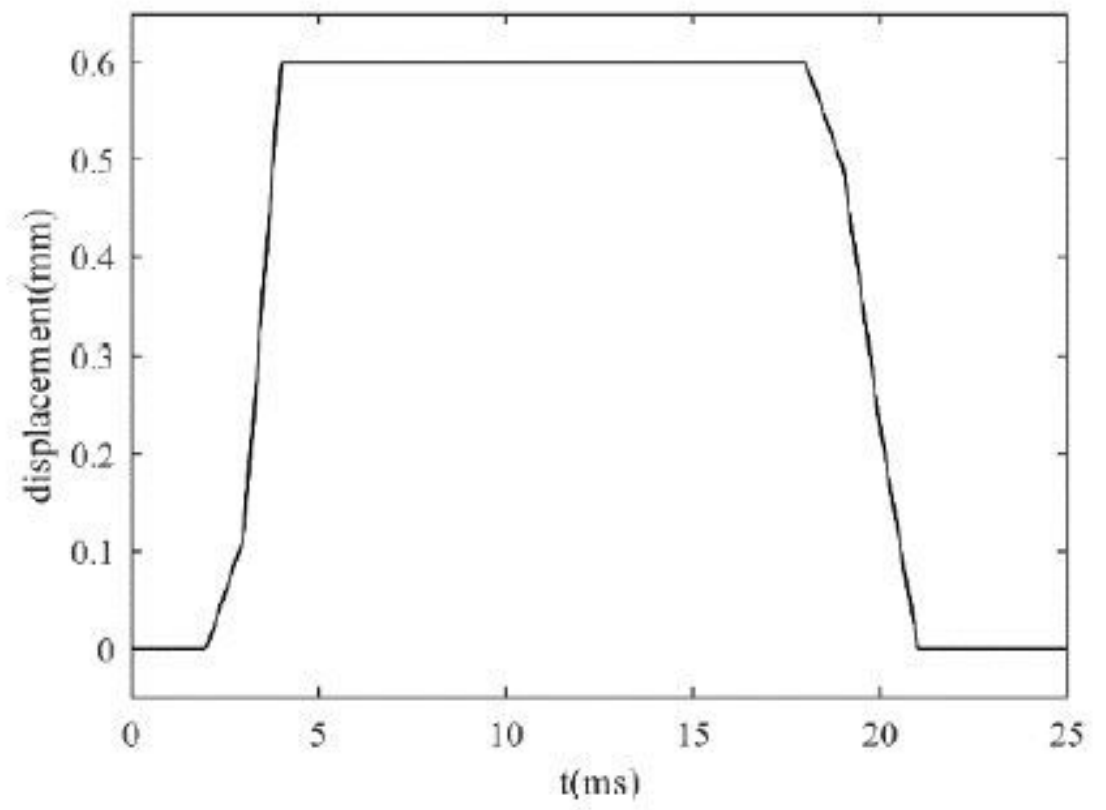

Figure 7

Opening and closing delay time of solenoid valve 


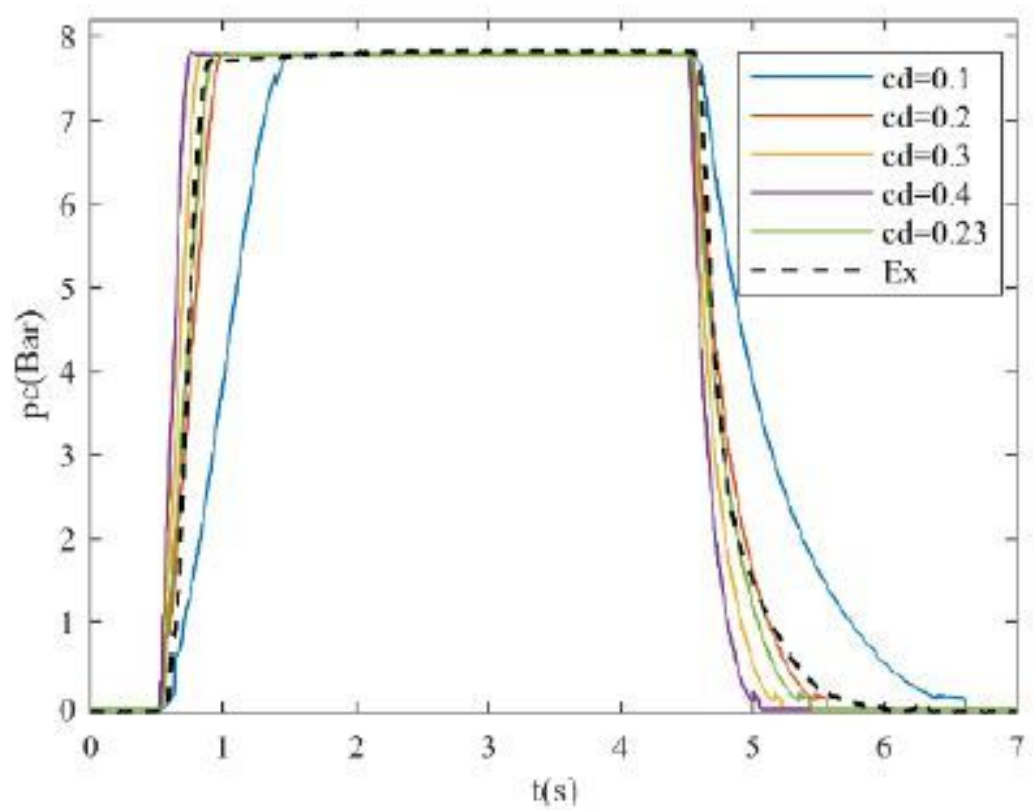

Figure 8

Comparison between actual pressure and calculated pressure in different $\mathrm{cd}$

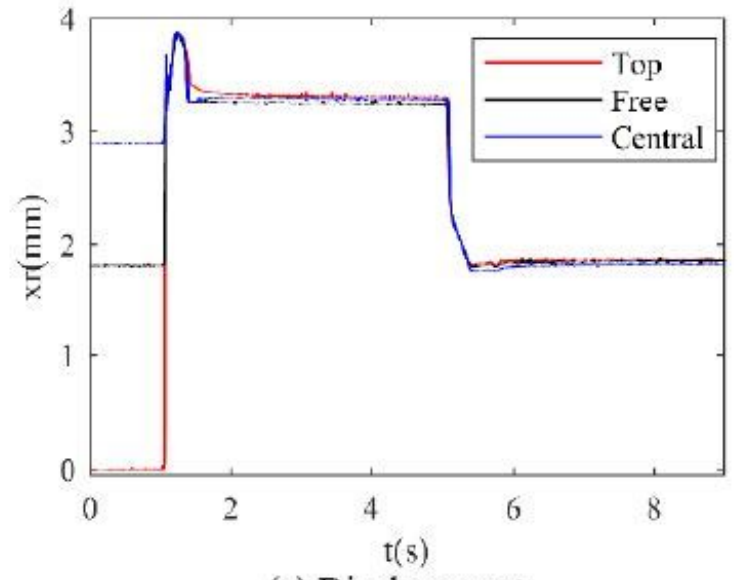

(a) Displacement

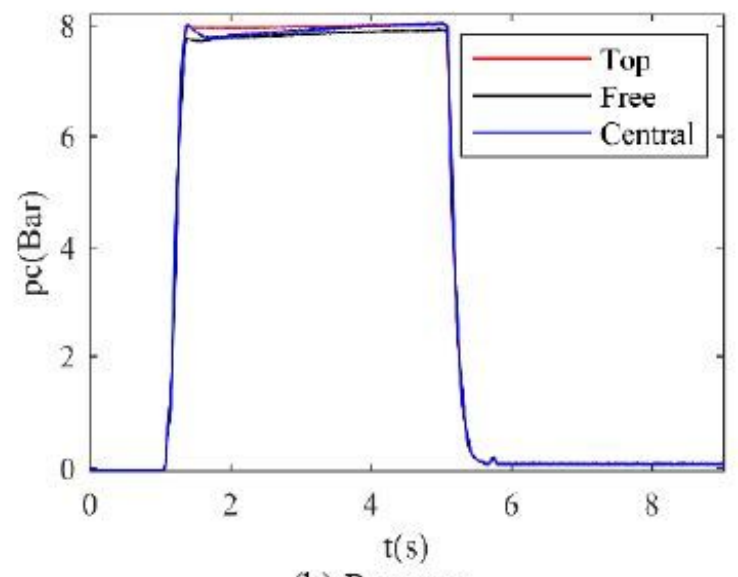

(b) Pressure

Figure 9

Comparison of different starting positions relay valve pistons 


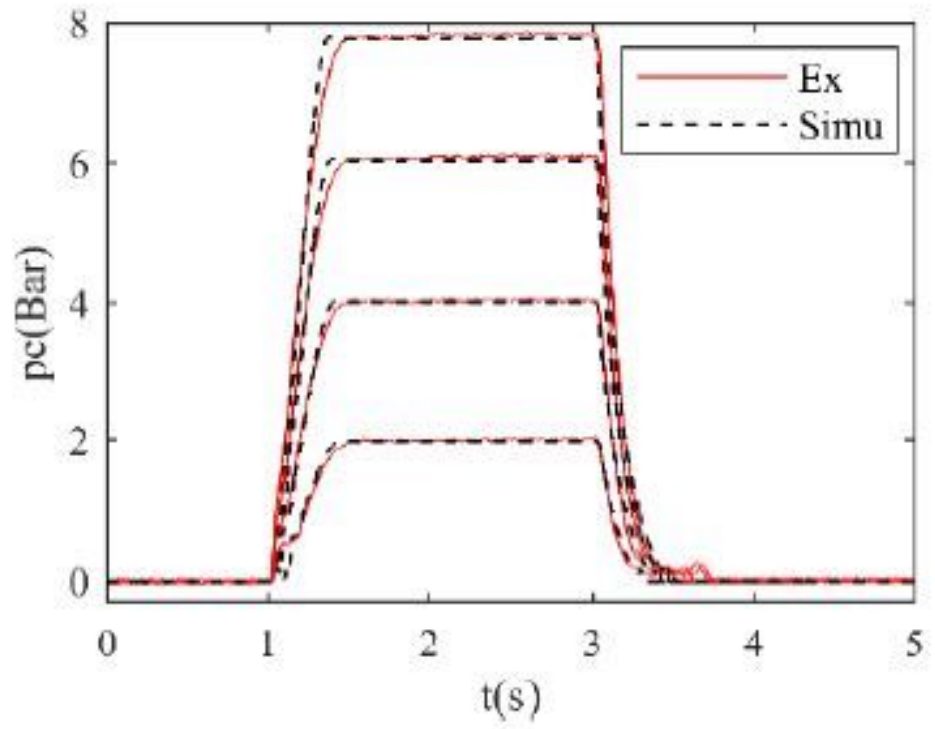

Figure 10

Static verification 


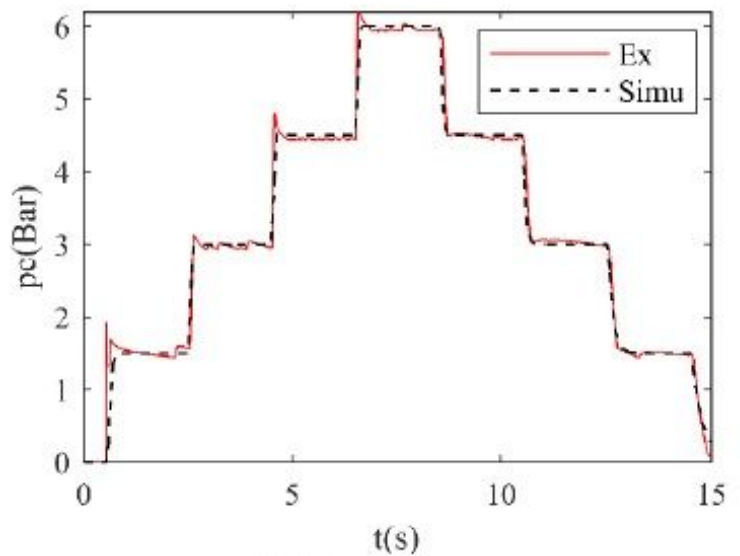

(a) Step response

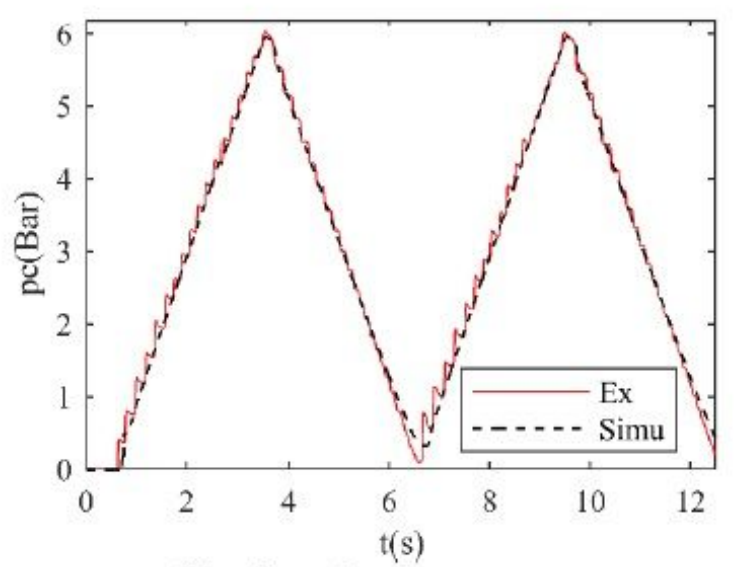

(b) Triangular wave response

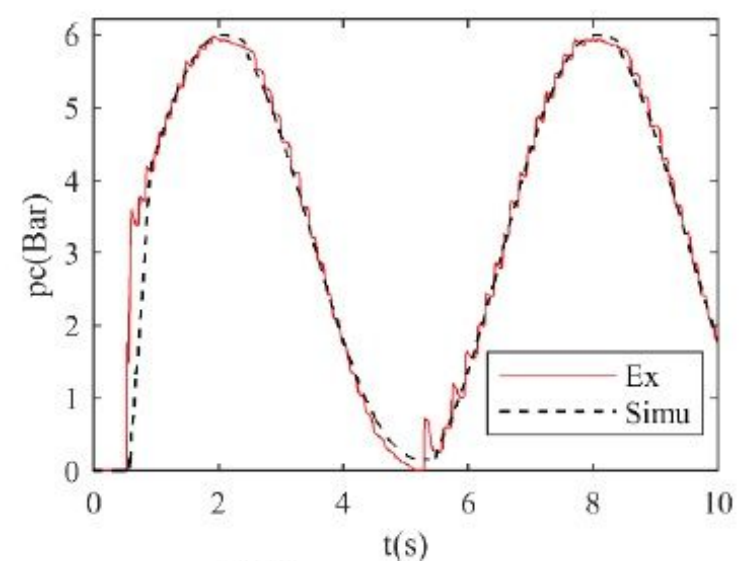

(c) Sin response

Figure 11

Dynamic verification 

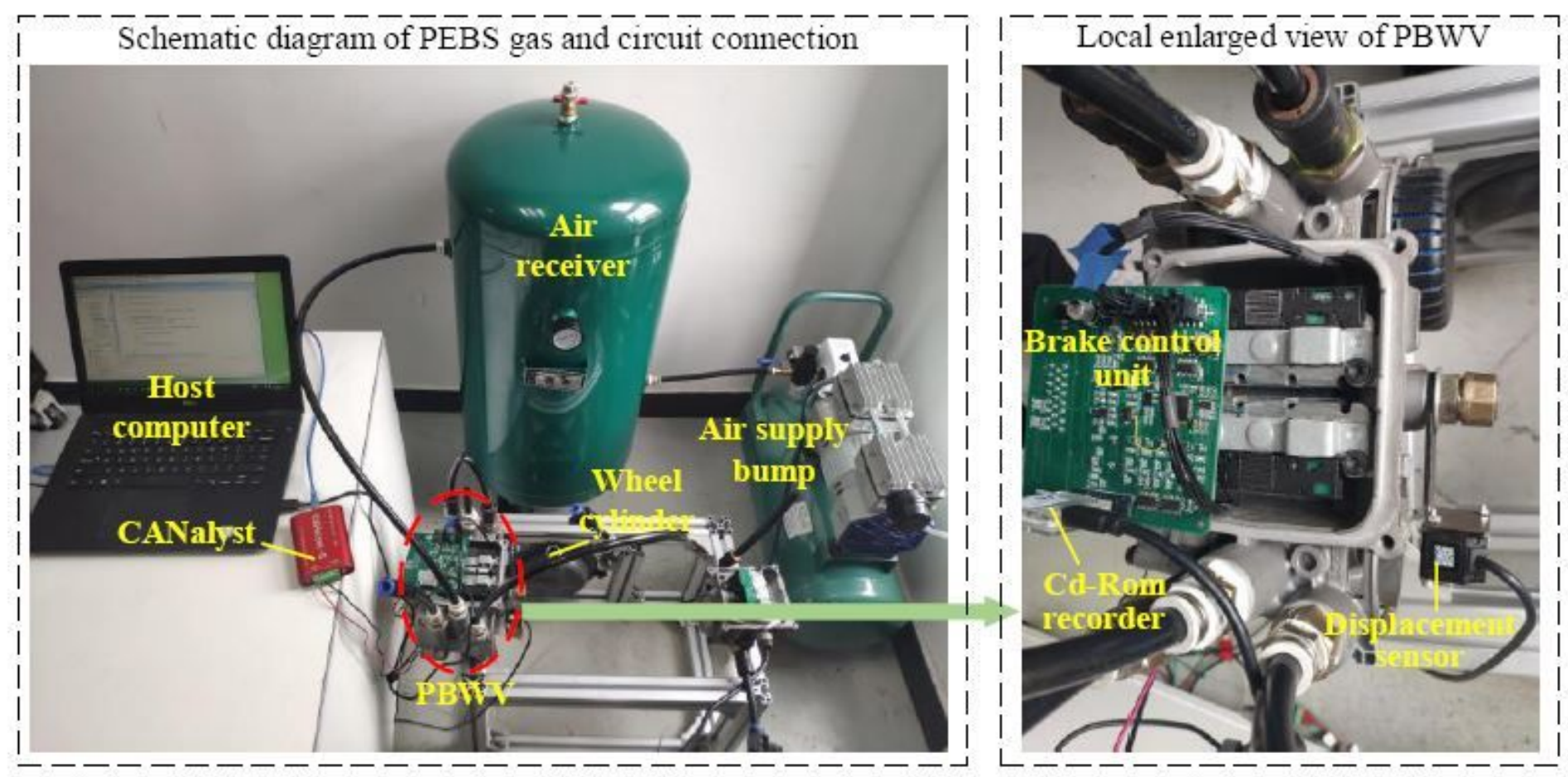

Figure 12

PEBS test bench 


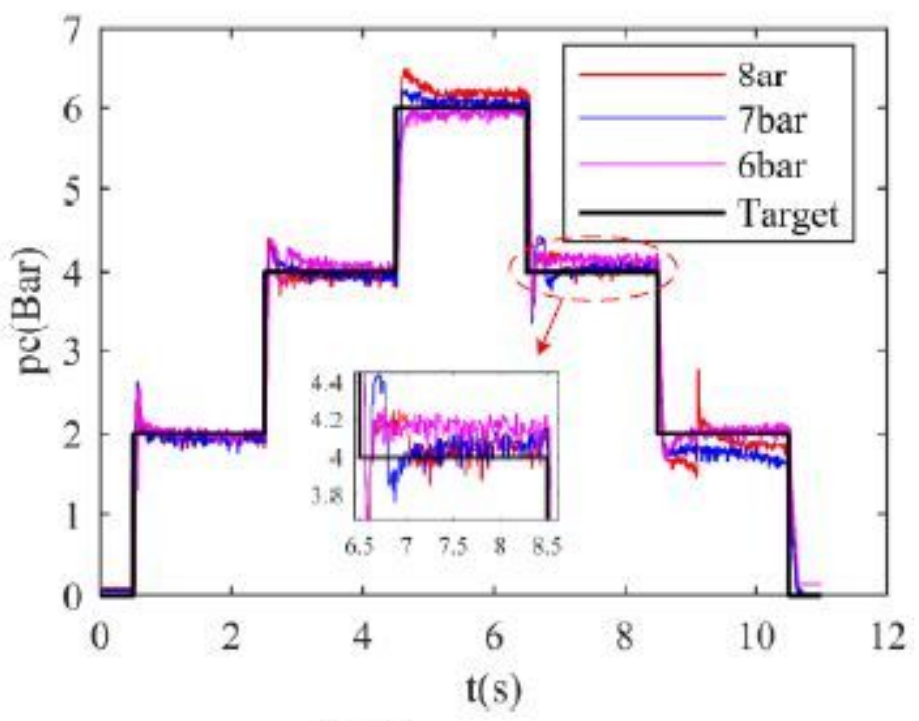

(a)Step response

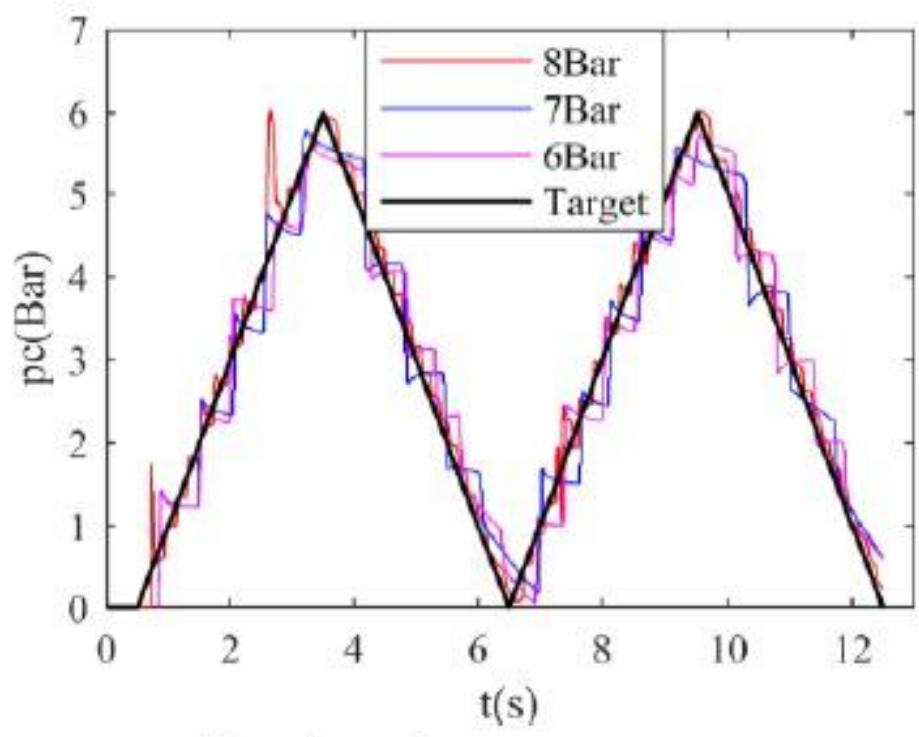

(b) Triangular wave response

Figure 13

Experimental results under the proportional control 


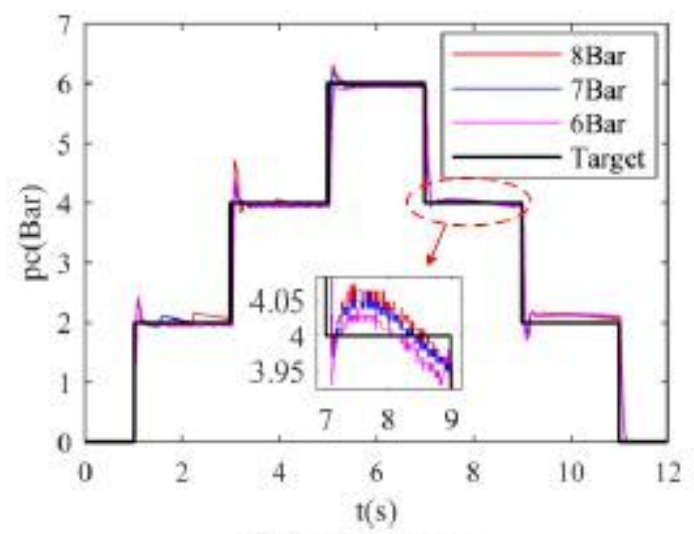

(a)Step response

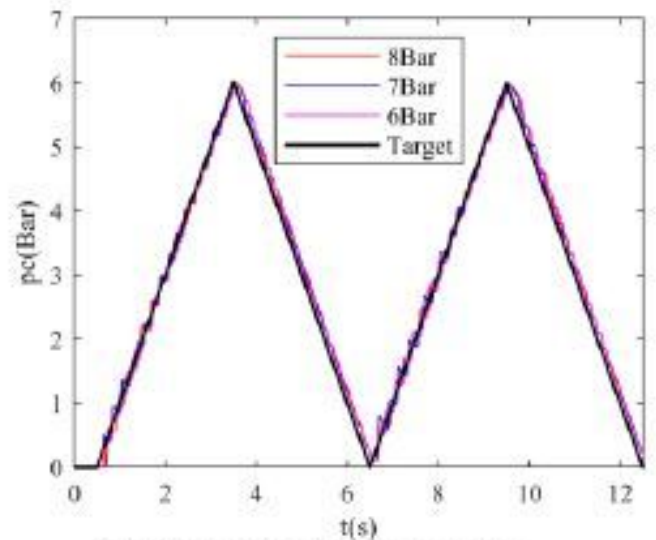

(b) Triangular wave response

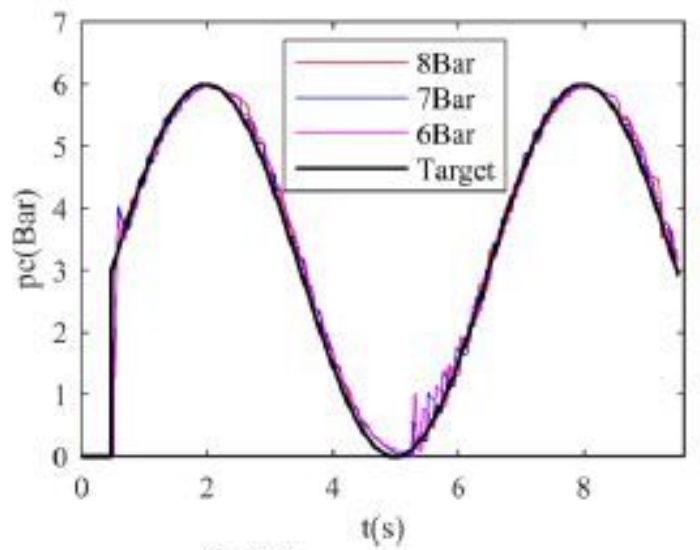

(c) Sin wave response

Figure 14

Experimental results under the AMPC and proportional control 


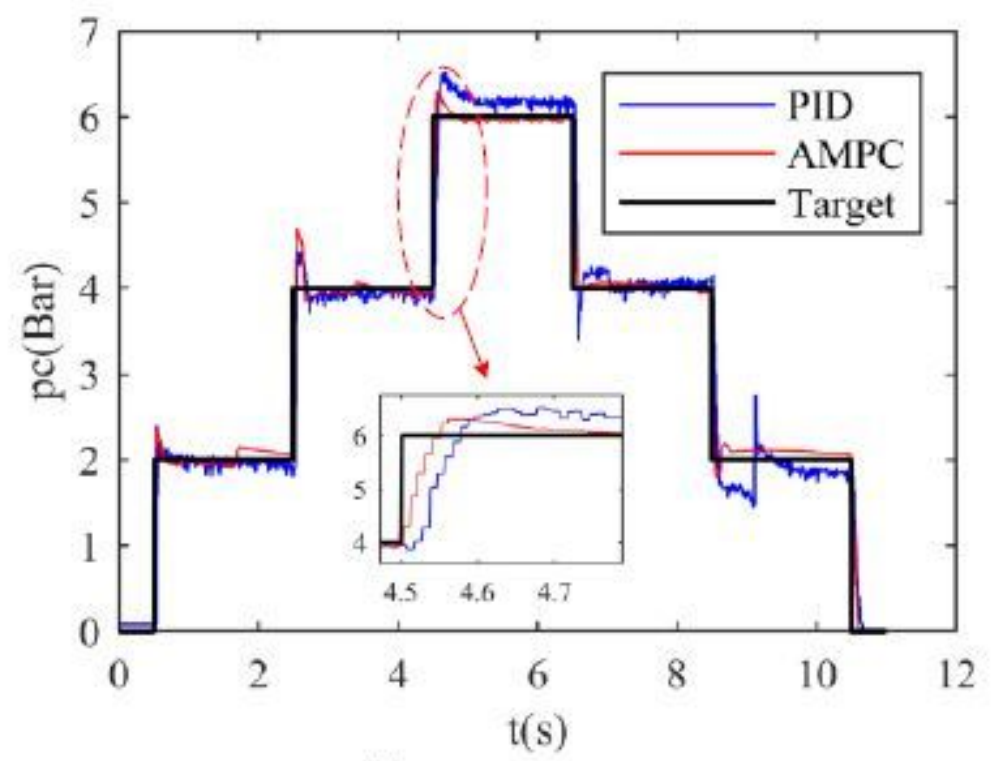

(a)Step response

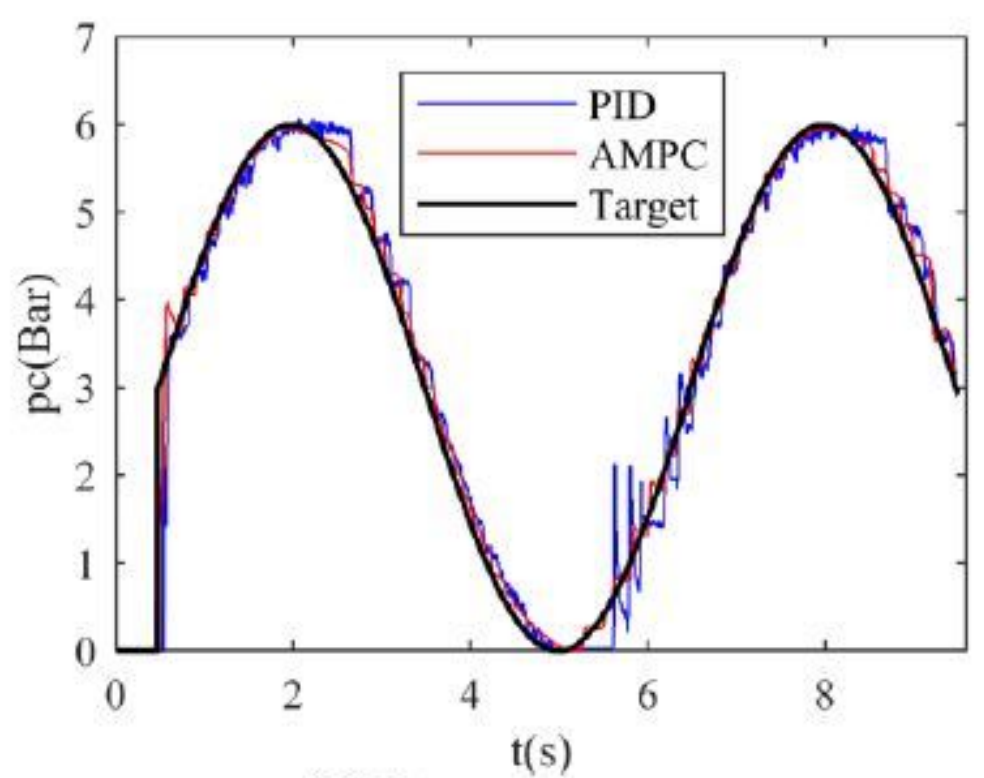

(b) Sin wave response

Figure 15

Comparison of response time between P and AMPC control algorithm 